\title{
Skeletal muscle dysfunction in patients with chronic obstructive pulmonary disease
}

\author{
Ho Cheol Kim' \\ Mahroo Mofarrahi ${ }^{2}$ \\ Sabah NA Hussain ${ }^{2}$ \\ 'Department of Internal Medicine, \\ College of Medicine, Gyeongsang \\ National University, Gyeongsang \\ University Hospital, Jinju, Korea; \\ ${ }^{2}$ Critical Care and Respiratory \\ Divisions, Royal Victoria Hospital, \\ McGill University Health Centre, \\ Montreal, Quebec, Canada
}

\begin{abstract}
Chronic obstructive pulmonary disease (COPD) is a debilitating disease characterized by inflammation-induced airflow limitation and parenchymal destruction. In addition to pulmonary manifestations, patients with COPD develop systemic problems, including skeletal muscle and other organ-specific dysfunctions, nutritional abnormalities, weight loss, and adverse psychological responses. Patients with COPD often complain of dyspnea on exertion, reduced exercise capacity, and develop a progressive decline in lung function with increasing age. These symptoms have been attributed to increases in the work of breathing and in impairments in gas exchange that result from airflow limitation and dynamic hyperinflation. However, there is mounting evidence to suggest that skeletal muscle dysfunction, independent of lung function, contributes significantly to reduced exercise capacity and poor quality of life in these patients. Limb and ventilatory skeletal muscle dysfunction in COPD patients has been attributed to a myriad of factors, including the presence of low grade systemic inflammatory processes, nutritional depletion, corticosteroid medications, chronic inactivity, age, hypoxemia, smoking, oxidative and nitrosative stresses, protein degradation and changes in vascular density. This review briefly summarizes the contribution of these factors to overall skeletal muscle dysfunction in patients with COPD, with particular attention paid to the latest advances in the field.
\end{abstract}

Keywords: skeletal muscles, chronic obstructive pulmonary disease, diaphragm, quadriceps, fatigue, disuse, atrophy, smoking, exercise

It has long been recognized that COPD is a systemic disease in which several extrapulmonary manifestations, including cachexia and skeletal muscle dysfunction, contribute to morbidity and mortality. Functionally, skeletal muscle dysfunction in COPD patients is characterized by significant reduction in muscle strength and endurance. It is structurally characterized by loss of muscle mass and cross-sectional area (muscle atrophy), fiber type distribution (reduction in the proportion of oxidative fibers and increases in the proportion of glycolytic fibers), oxidative metabolic capacity (attenuation of mitochondrial enzyme activities and expression) and capillary distribution ( significant loss of capillary density). Although disuse and inactivity are important contributors to the pathogenesis of skeletal muscle dysfunction in COPD patients, several other systemic and local factors are also involved. These include systemic inflammation, malnutrition, corticosteroid usage, hypoxemia, aging, smoking and local factors such as the production of reactive oxygen (ROS) and nitrogen species (RNS) and enhanced protein degradation inside muscle fibers, a result of increased activities of the proteasomal and lysosomal pathways and activation of calpains and caspases.

Correspondence: Sabah NA Hussain Critical Care and Respiratory Divisions, 687 Pine Avenue W, Royal Victoria Hospital, McGill University Health Centre, Montreal, QC, Canada H3A IAI

$\mathrm{Tel}+\mathrm{I} 5148431664$

$\mathrm{Fax}+$ I 5148431686

Email sabah.hussain@muhc.mcgill.ca

\section{Evidence of skeletal muscle dysfunction in patients with COPD}

It has been well established that skeletal muscle function (strength and endurance) and structure (fiber size, fiber type distribution, capillary density and metabolic capacity) 
are altered in patients with COPD. Specific abnormalities of these muscles include depressed muscle strength, reduction in muscle endurance, muscle fiber atrophy, and fiber type shift.

\section{Depressed muscle strength}

Alterations in muscle strength (defined as the capacity of the muscle to generate force) in COPD patients primarily involves the lower limb muscles, with quadriceps femoris muscle strength being $20 \%$ to $30 \%$ lower in patients with moderate to severe COPD as compared to control subjects (Gosselink et al 1996; Bernard et al 1998; Franssen et al 2005). The degree of reduced limb muscle strength correlates with the severity of the disease process (Bernard et al 1998) (Figure 1). In addition, it has been well established that reduced limb muscle strength in patients with moderate COPD contributes to poor exercise performance, increased dyspnea and worsening of quality of life (Gosselink et al 1996; Mostert et al 2000). Furthermore, relatively low limb muscle strength is a powerful predictor of mortality in severe COPD patients (Swallow et al 2007b).

\section{Reduction in muscle endurance}

Many reports have confirmed that the endurance (defined as the capacity of the muscle to maintain a certain force over time) of limb muscles is attenuated by about $30 \%$ in patients with moderate COPD and that poor muscle endurance in these patients correlates positively with physical activity index, forced expiratory volume in one second $\left(\mathrm{FEV}_{1}\right)$ and resting partial pressure of oxygen in arterial blood $\left(\mathrm{PaO}_{2}\right)$ (Serres et al 1998; Van't et al 2004). Allaire and colleagues (2004) have concluded that attenuation of quadriceps muscle endurance in COPD patients is related to reduced oxidative capacity of the mitochondria and to the development of oxidative stress in the muscle. Recently, this reduction of muscle endurance time has been confirmed using artificial stimulation protocols (Figure 2) (Swallow et al 2007a).

\section{Muscle fiber atrophy}

It has been well established that limb muscles of COPD patients develop significant reductions in mass and crosssectional areas (Engelen et al 2000c; Hopkinson et al 2007). The magnitude of loss of thigh muscle mass is relatively greater than that of whole body weight, indicating a preferential loss of muscle tissue over other body tissues in emaciated COPD patients (Bernard et al 1998). The degree to which fiber atrophy contributes to reduced limb muscle strength in these patients remains debatable. On one hand, several reports have described that when limb muscle strength is normalized per cross-sectional area or mass, no differences can be observed between COPD patients and control subjects (Bernard et al 1998; Engelen et al 2000a, 2000c). This conclusion is supported by the observation that in vitro maximum tetanic tension of vastus lateralis muscles, normalized per muscle bundle cross-sectional area, is similar in COPD patients and control subjects (Debigare et al 2003a). These studies clearly lend credence to the notion that muscle atrophy is the sole cause of reduced limb muscle strength and endurance in COPD patients. On the other hand, Malaguti and colleagues (2006) have used standard ratio, power function ratio and analysis of covariance to normalize isokinetic dynamometry parameters (peak torque, isometric strength and total work) of leg muscles to leg muscle mass and have shown that greater muscle mass is needed to generate a given functional output in COPD patients as compared with control subjects. As such, they suggest that factors other than atrophy might play a role in explaining skeletal muscle dysfunction in COPD patients (Malaguti et al 2006). Their position is supported by several reports that have documented the presence of intrinsic abnormalities inside limb muscle fibers of COPD patients, especially in the form of contractile fatigue (Mador et al 2000, 2001, 2003a, 2003b; Saey et al 2003, 2005, 2006). A good example of these reports is that of Mador and colleagues (Jeffery et al 2000) who found a significant decrease in quadriceps twitch force of patients with severe COPD - by more than $20 \%$ within $30 \mathrm{~min}$ of termination of exercise - a value that was significantly greater than that observed in control subjects. Furthermore, Mador and colleagues (2003a) have also compared the degree of fatigability in limb muscles of COPD patients and control subjects exercising at work loads designed to generate similar absolute oxygen consumption and have described significantly greater falls in quadriceps muscle twitch force in COPD patients than in control subjects, suggesting that limb muscles of COPD patients are more fatigable than those of healthy individuals.

\section{Fiber type shift}

In severe COPD patients, quadriceps muscles undergo significant redistribution of fiber type ratios, manifested as a reduction in the proportion of type I (slow-twitch oxidative) fibers and augmentation of the proportion of type $\mathrm{IIb}$ (fast twitch glycolytic) fibers. An early report by Whittom and colleagues (1998) demonstrated that type I fiber proportion declines by $20 \%$, whereas the proportion of type IIb fibers increases by $10 \%$ in patients with severe COPD. A subsequent 
A

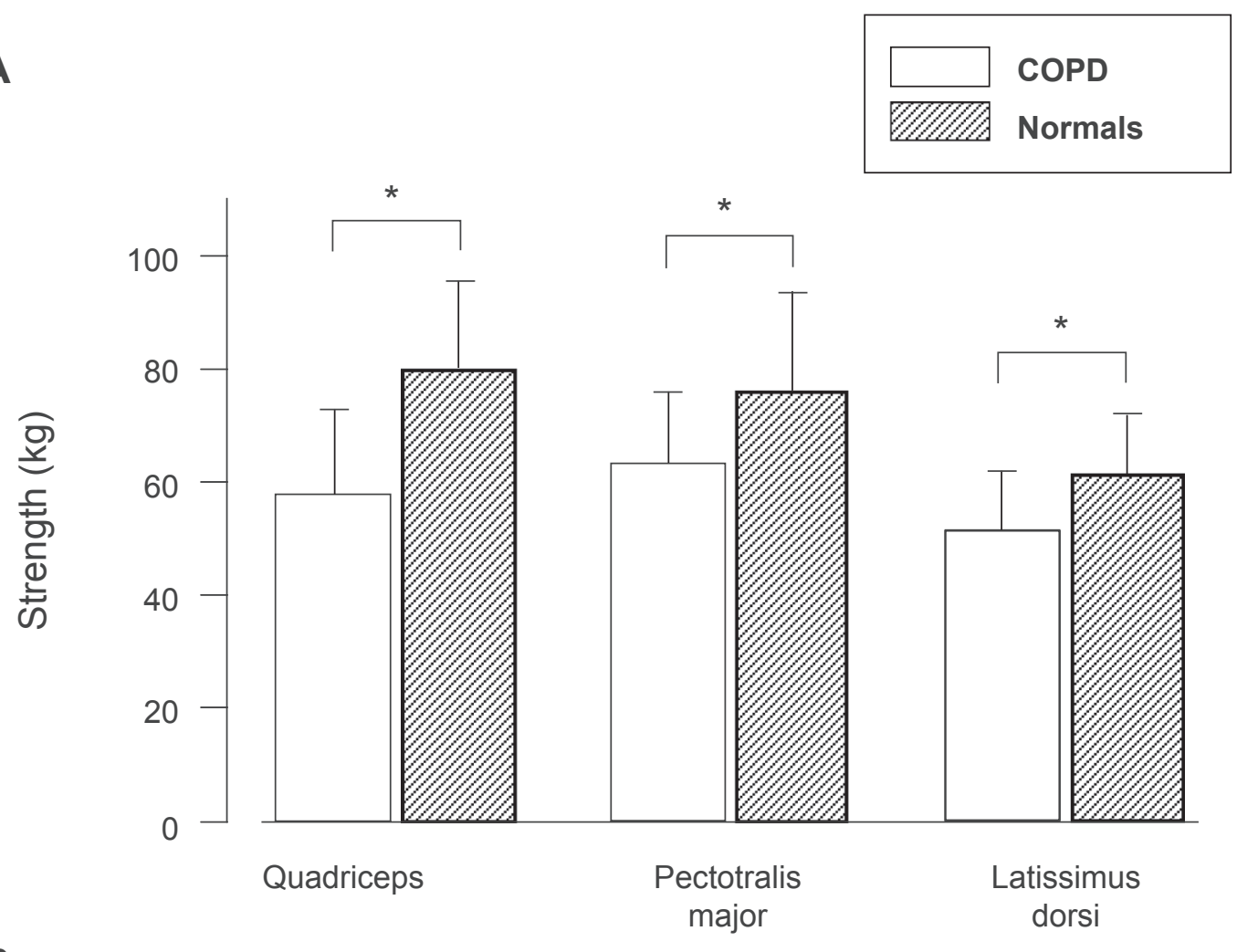

B

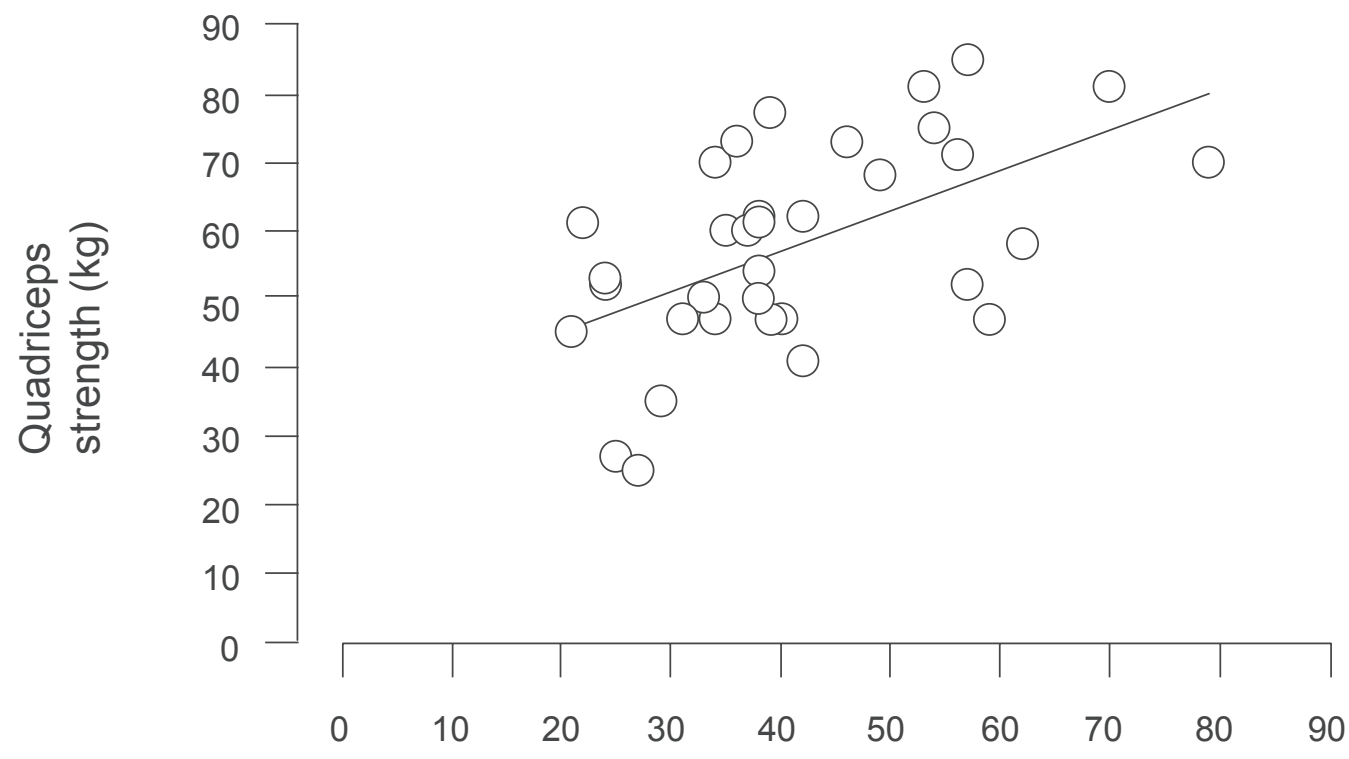

$\mathrm{FEV}_{1}(\%$ predicted $)$

Figure I A) Group mean values $( \pm S D)$ for strength of quadriceps, pectoralis major and latissimus dorsi muscles obtained from normal subjects and COPD patients. Note significant reduction in strength in each of three muscle groups in patients with COPD, as compared to normal subjects. *P $<0.05$. B) Relationship between $\mathrm{FEV}$, (percentage of predicted) and quadriceps muscle strength showing significant positive relationship $(r=0.55, p<0.0005)$ Copyright $(C)$ 1998. Adapted from Bernard $S$, LeBlanc $P$, Whittom $F$, et al 1998. Peripheral muscle weakness in patients with chronic obstructive pulmonary disease. Am J Respir Crit Care Med, I58:629-34. Abbreviations: COPD, chronic obstructive pulmonary disease; $\mathrm{FEV}_{1}$, forced expiratory volume in one second. 
study by Maltais and colleagues (1999) confirmed a shift toward type II fibers and a reduction in the proportion of type I fibers in the vastus lateralis muscles of patients with severe COPD. Recent meta-analysis has revealed that the proportion of type I fibers in the vastus lateralis muscle correlates with $\mathrm{FEV}_{1}, \mathrm{FEV}_{1}$ /forced vital capacity (FVC) and the body mass index (BMI) in patients with moderate to severe COPD (Gosker et al 2007b). Although the exact functional consequences of this fiber type redistribution remain under investigation, the fact that type II fibers are fatigue-prone suggests that an increased proportion of type II fibers might be an important factor in increased leg muscle fatigability and reduced endurance. It should be emphasized that fiber type shifting towards more glycolytic fibers in limb muscles of COPD patients is associated with reductions in muscle oxidative capacity, as shown by significantly lower levels of cytochrome c oxidase and succinate dehydrogenase in the quadriceps of patients with severe COPD (Gosker et al 2002). In a subsequent study, Gosker and colleagues (2007a) have reported that reduced oxidative capacity of the quadriceps of COPD patients can be attributed, in part, to reduction in mitochondrial density in that muscle. The exact mechanisms responsible for reduced mitochondrial density in limb muscles of COPD patients are as yet unclear, however recent observations of Remels and colleagues (2007), that peroxisome proliferator-activated receptors (PPARs), PPAR- $\gamma$ co-activator PGC- $1 \alpha$ and the mitochondrial transcription factor A (TFAM) are significantly lower in quadriceps of cachectic patients with severe COPD, suggest that mitochondrial biogenesis is significantly reduced in limb muscles of these patients.

\section{Consequences of skeletal muscle dysfunction in patients with COPD}

Reduced exercise capacity and dyspnea on exertion are the most common complaints in patients with COPD. These symptoms cannot be explained entirely on the basis of a decline in lung function and impaired gas exchange. Indeed, Killian and colleagues (1992) measured leg effort and dyspnea in 97 patients with chronic airway obstruction during maximal cycle ergometry and concluded that the intensity of leg effort is more crucial than the degree of dyspnea. In addition, observations that considerable exercise limitation persists in COPD patients who have undergone lung transplantation, despite marked improvement in lung function, and in COPD patients that have experienced an improvement in airway obstruction by using bronchodilators, provides evidence in favor of a poor relationship between lung function and exercise performance (Lands et al 1999; Saey et al 2003).

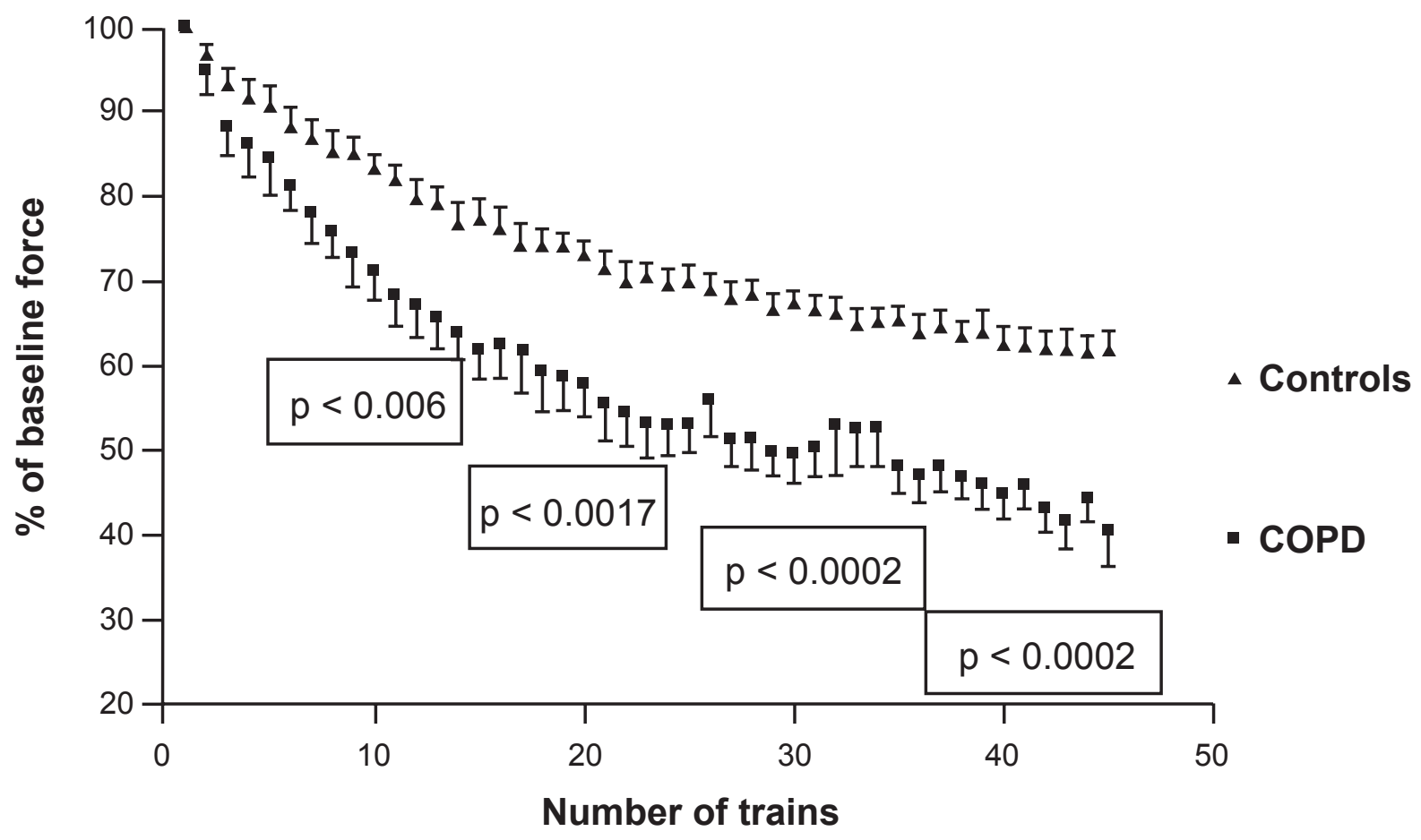

Figure 2 Force decline of quadriceps femoris muscle during repetitive magnetic stimulation of femoral nerve in control subjects and COPD patients. The curves were significantly different at 10,20,30, and 40 trains Copyright @ 2007 . Adapted from Swallow EB, Gosker HR, Ward KA, et al 2007a.A novel technique for nonvolitional assessment of quadriceps muscle endurance in humans. J Appl Physiol, 103:739-46.

Abbreviation: COPD, chronic obstructive pulmonary disease. 
Reduced exercise capacity and limb muscle weakness lead to COPD patient disability and correlate with higher utilization of health care resources. This conclusion is supported by Decramer and colleagues (1997) in their analysis of factors associated with higher utilization of health care resources in 57 stable severe COPD patients. They have shown that quadriceps muscle force alone, rather than pulmonary function and exercise capacity, is a significant determinant of higher utilization of health care resources. Montes de Oca and colleagues (2006) have reached a similar conclusion. Skeletal muscle dysfunction also contributes to poor clinical outcomes, as indicated by a significant relationship between mid-thigh cross-sectional area and mortality in stable COPD patients (Marquis et al 2002).

\section{Ventilatory muscle function}

There is increasing evidence that the degree of skeletal muscle dysfunction in COPD patients is not homogenous between various muscle groups. Indeed, Gosselink and colleagues (2000) have found that inspiratory muscle strength is more severely reduced than that of expiratory muscle strength and that proximal upper muscle strength is more impaired than distal upper limb strength in patients with moderate COPD. Similarly, Franssen and colleagues (2005) have described a relatively milder reduction in arm strength than that of leg strength, which is more severely attenuated. The reasons behind these differences between various skeletal muscles remain unclear, however many investigators have proposed that daily muscle recruitment and activation largely determines the degree to which a given muscle is affected in these patients. For instance, the ventilatory muscles, particularly the diaphragm, have different workloads than do the lower limb muscles. Ventilatory muscles are in a chronically overloaded state due to increased work of breathing brought on by airflow obstruction and hyperinflation.

In contrast, limb muscles, especially lower extremity muscles, are in a chronically underloaded state due to chronic inactivity and disuse. These dissimilar loading patterns are the likely cause of biochemical and structural adaptations that develop in the ventilatory muscles but that are not present in lower limb muscles of COPD patients. For instance, the diaphragms of patients with severe COPD have increased proportions of type I fibers as compared with control subjects. This was documented for the first time by Levine and colleagues (1997) who reported that the proportion of type I fibers averages $64 \%$ of total fibers in the diaphragms of patients with severe COPD whereas the proportion of these fibers averages only $45 \%$ of total fiber number in control diaphragms. It should be emphasized that this rise in the proportion of type I fibers in the diaphragm is evident only in severe, as opposed to moderate, COPD patients (OrozcoLevi et al 1999; Orozco-Levi 2003).

Levine and colleagues (2003) have also demonstrated that a negative exponential relationship exists between the proportion of type I fibers in the diaphragm and resting $\mathrm{FEV}_{1}$ (\% predicted), implying that a reduction in $\mathrm{FEV}_{1}$ down to $60 \%$ predicted value has no influence on the proportion of type I fibers, and that a further decline in $\mathrm{FEV}_{1}$ is accompanied by a significant increase in the proportion of these fibers. These results suggest that diaphragm fiber type switching, to more fatigue resistant fibers, is highly dependent on the severity of the pulmonary disease process in COPD patients. Moreover, fiber type switching toward an increase in proportion of type I fibers is not limited to the diaphragm but can also be observed in other inspiratory muscles. Indeed, Levine and colleagues (2006) have reported an increase in the proportion of type I fibers, from an average of $51 \%$ in the parasternal intercostals of control subjects to $73 \%$ in the same muscles of patients with severe COPD.

Other adaptive changes that have been observed in the diaphragm of COPD patients include increased mitochondrial density, increased oxidative capacity and enhanced myosin ATPase activity (Orozco-Levi et al 1999; Levine et al 2002). Additionally, relatively shorter sarcomere lengths have been measured in the diaphragms of COPD patients with hyperinflation, as compared to those without hyperinflation (Levine et al 1997; Orozco-Levi et al 1999). This shortening of diaphragm sarcomeres represents an adaptive response designed to reverse the negative influence of hyperinflation on the force-length characteristics of the diaphragm that helps to preserve diaphragm fiber capacity to generate tension. It should be emphasized that despite several compensatory adaptations in the diaphragm of COPD patients, maximal strength of this muscle, as measured by maximal transdiaphragmatic pressure $\left(\mathrm{Pdi}_{\max }\right)$, remains about 30 to $40 \%$ lower in COPD patients as compared with control subjects (Bellemare and Grassino 1983; Polkey et al 1996). Gosselink and colleagues (2000) have also reported that inspiratory muscle strength in patients with severe COPD, as measured by maximal inspiratory pressure, averaged $59 \%$ of that measured in control subjects.

Reduction of diaphragm strength in COPD patients has been traditionally attributed to hyperinflation-induced shortening of diaphragmatic length, which has a negative influence on the pressure-length relationship. This view is supported by the observation that lung volume reduction 
surgery results in an increase in diaphragm length and restoration of $\mathrm{Pdi}_{\text {max }}$ in COPD patients (Lando et al 1999). Moreover, intrinsic abnormalities within diaphragm muscle fibers cannot be ruled out as significant contributors to the reduced strength of this muscle in COPD patients. Indeed, Levine and colleagues (2003) measured maximal isometric force of single muscle fibers obtained from the diaphragm of two severe COPD patients and reported that maximal force of type I and IIa fiber was significantly lower in these patients than in control subjects. Reduction in force generation of isolated diaphragm muscle fibers has also been documented in patients with mild to moderate COPD (Ottenheijm et al 2005). This observation cannot simply be attributed to muscle fiber atrophy and the reduction of levels of myofilament proteins since significant reduction in $\mathrm{Ca}^{++}$sensitivity of skinned muscle fibers and impaired cross-bridge cycling kinetics can also be observed in the diaphragms of COPD patients (Ottenheijm et al 2005; Stubbings et al 2008).

Other intrinsic abnormalities in the diaphragm of COPD patients include reduced passive-tension generation of diaphragm single fibers. This condition can be attributed, in part, to selective alternative splicing of the titin gene, resulting in increased length of the elastic segment of the protein that is rich in proline, glutamate, valine, and lysine (Ottenheijm et al 2006a). In addition, the diaphragms of COPD patients manifest increased susceptibility to sarcomere injuries, both at the basal level and in response to increased activation of the muscle during resistive loading (Orozco-Levi et al 2001).

COPD also induces upper limb muscles to develop adaptive changes that are different from those detected in lower limb muscles. For instance, Gea and colleagues (2001) compared exercise performance, handgrip strength and metabolic profile of the deltoid muscles and found that handgrip strength changes very little in COPD patients, despite a marked reduction in exercise capacity. In addition, while deltoid muscle creatine kinase and phosphofructokinase activities do not differ among COPD patients and control groups, the activities of citrate synthase and lactate dehydrogenase are significantly greater in COPD patients, suggesting the presence of metabolic adapative changes in both mitochondrial oxidative capacity and glycolysis pathways (Gea et al 2001; Hernandez et al 2003).

\section{Mechanisms of skeletal muscle dysfunction in COPD patients}

Potential mechanisms of skeletal muscle dysfunction in COPD patients are summarized in Figure 3. Skeletal muscle dysfunction in COPD patients can be attributed to a set of complex interactions between many factors, both systemic and local.

\section{Systemic factors}

It has long been recognized that systemic factors such as inflammation, malnutrition, medication, inactivity, age,

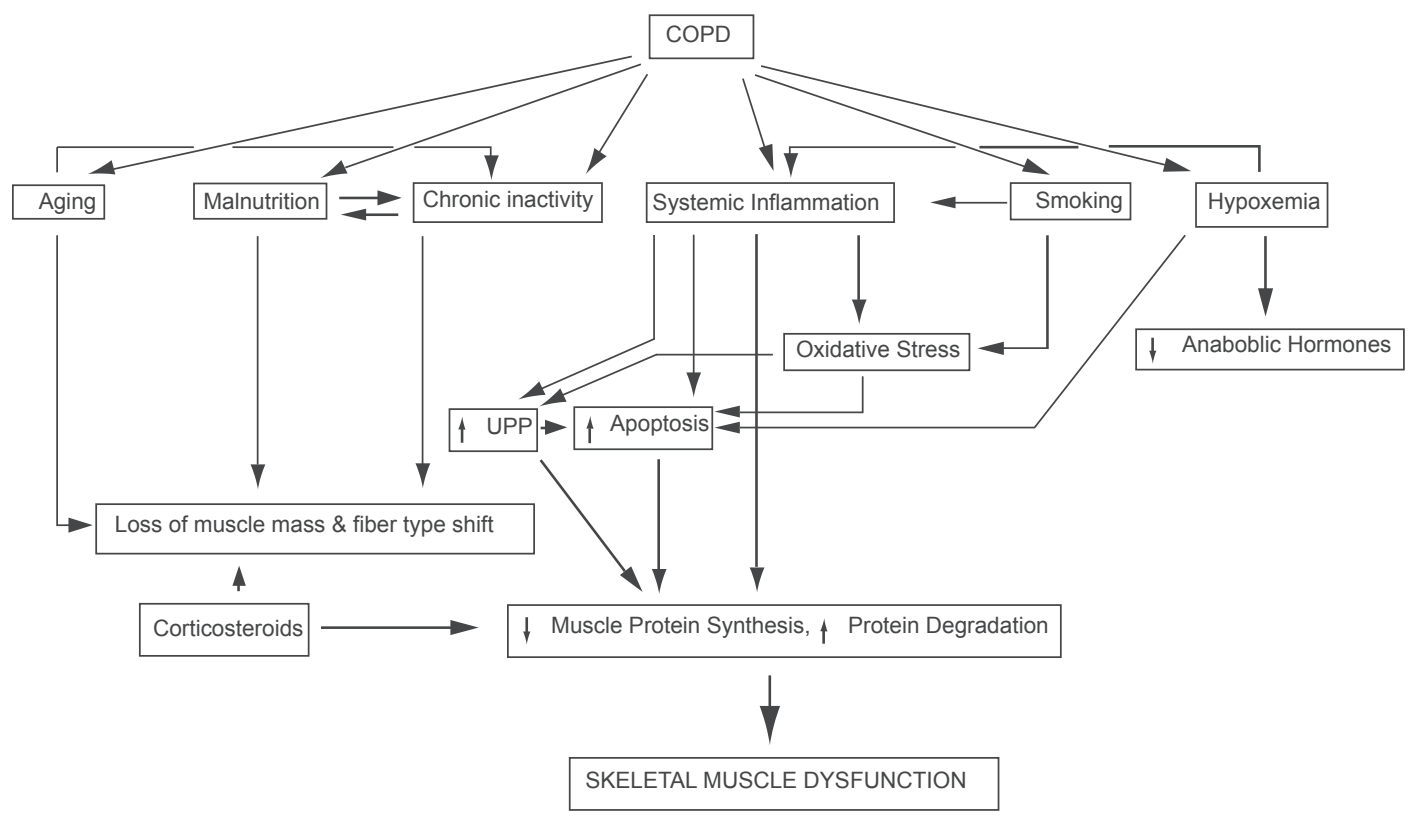

Figure 3 Proposed mechanisms of skeletal muscle dysfunction in COPD patients.

Abbreviations: COPD, chronic obstructive pulmonary disease; UPP, ubiquitin/proteasomal pathway. 
hypoxemia, and smoking exert strong effects on skeletal muscle performance in COPD patients.

\section{Inflammation}

Systemic and/or local inflammation has been identified as a common feature of COPD. In stable COPD patients, elevated serum levels of C-reactive protein, fibrinogen, circulating leukocytes and pro-inflammatory cytokines, including tumor necrosis factor-alpha (TNF $\alpha$ ), interleukin-8 (IL8), IL6, soluble TNF receptors 55 (sTNF-R55) and 72 (sTNF-R75) have been observed (Schols et al 1996; Dentener et al 2001; Gan et al 2004). Recently, significant elevations in serum IL18 have been observed in patients with moderate to severe COPD (Petersen et al 2007b). The cellular origins of pro-inflammatory cytokines in the serum of stable COPD patients remain unclear. One likely source is the lungs, where intense inflammatory processes develop in the vasculature, parenchyma and airways. However, no direct correlations have been found between sputum and plasma concentrations of IL8, sTNF-R55 and sTNF-R75 in patients with mild to moderate COPD (Vernooy et al 2002), suggesting that organs other than the lungs contribute to elevated levels of systemic inflammatory mediators. One such organ is skeletal muscle, particularly the diaphragm and intercostal muscles, where the work of breathing in COPD patients is elevated. This view is based on the observations that strenuous resistive breathing and whole body exercise in healthy humans, such as treadmill running, induce significant elevations of plasma pro-inflammatory cytokine levels, including IL6, IL-1 $\beta$, and TNF $\alpha$ and that this production is mediated in part by increased oxygen radical production (Vassilakopoulos et al 1999, 2002; Ostrowski et al 1998). This role of ventilatory muscles as a source of systemic inflammation has been confirmed in an animal model of inspiratory resistive loading, where increased work of breathing significantly upregulates IL6, IL1 $\beta$ and TNF $\alpha$ expressions within the diaphragm (Vassilakopoulos et al 2004). A recent study by Casadevall and colleagues (2007) has confirmed that TNF $\alpha$ and IL6 levels are significantly elevated in the intercostal muscles of COPD patients.

The involvement of inflammatory mediators in skeletal muscle dysfunction is also suggested by the observation that systemic inflammation markers correlate with poor muscle contractile performance in COPD patients. For example, quadriceps muscle strength correlates negatively with serum IL8 levels in COPD patients during exacerbation and with serum IL6 and TNF $\alpha$ in aged COPD patients (Spruit et al 2003; Yende et al 2006). Other authors have revealed that low $\mathrm{FEV}_{1}$ values correlate with increased plasma levels of C-reactive protein and IL6 in severe to very severe COPD cases and that elevated C-reactive protein levels associate not only with diminished limb muscle strength but also with reduced exercise endurance and poor health status and quality of life, independent of other factors such as age, sex, and smoking history (Broekhuizen et al 2006; Pinto-Plata et al 2006).

The notion that systemic inflammation contributes to skeletal muscle dysfunction in COPD patients is also supported by the fact that many pro-inflammatory cytokines can adversely influence skeletal muscle growth and contractile performance. This is particularly true with TNF $\alpha$, which promotes muscle wasting by enhancing the activity of the ubiquitin proteasome pathway (Langen et al 2006). TNF $\alpha$ also promotes muscle wasting by inducing apoptosis (Carbo et al 2002). Loss of nuclei, a result of increased apoptosis in skeletal muscle fibers, alters myonuclear domain size (the amount of cytoplasm per myonucleus), eventually resulting in muscle atrophy. The involvement of apoptosis in limb muscle wasting in COPD patients was first proposed by Agusti and colleagues (2002), who described increased numbers of apoptotic nuclei in quadriceps muscles of these patients. TNF $\alpha$ might also reduce skeletal muscle oxidative capacity by inhibiting mitochondrial biogenesis (Valerio et al 2006). Finally, TNF $\alpha$ exerts acute inhibitory effects on muscle contractility (Wilcox et al 1996), which has been attributed to depressed sensitivity of myofilament proteins to $\mathrm{Ca}^{++}$and to enhanced generation of ROS and RNS (Reid et al 2002).

It should be emphasized that despite convincing documentation of elevated circulating levels of pro-inflammatory cytokines in stable COPD patients, as well as in those suffering from acute exacerbations, general agreement is lacking about the degree to which pro-inflammatory mediators are upregulated in limb muscles. On one hand, Barreiro and colleagues (2008b) measured various pro-inflammatory cytokines in quadriceps muscles of 19 patients with severe COPD and substantial muscle atrophy and reported that IL6, IL1 $\beta$, interferon- $\gamma$ and TGF- $\beta$ levels were not significantly different from those detected in control subjects. TNF $\alpha$ expression was actually lower in quadriceps muscles of COPD patients as compared with control subjects (Barreiro et al 2008b). Similarly, Crul and colleagues (2007) failed to detect significant elevations of IL8, IL6 and TNF $\alpha$ in quadriceps muscles of hospitalized and clinically stable COPD patients, as compared with age-matched control subjects. 
On the other hand, Montes de Oca and colleagues (2005) have described a more than fivefold increase in TNF $\alpha$ levels in quadriceps of patients with severe COPD, as compared with control subjects. A significant increase in NFKB nuclear binding activity (a major regulator of cytokine production) has also been observed in limb muscles of patients with severe COPD (Agusti et al 2004). More recently, Petersen and colleagues (2007b) have described significant upregulation of IL18 in quadriceps muscle samples obtained from patients with moderate to severe COPD. The reasons behind these contradictory results are as yet unclear, but factors such as the use of relatively low numbers of patients, the presence or absence of hypoxemia, severe weight loss, exacerbation of pulmonary manifestations and the development of oxidative stress inside muscle fibers might be involved.

\section{Malnutrition}

The importance of nutritional status on exercise performance and skeletal muscle dysfunction in COPD patients stems from the fact that over $30 \%$ of COPD patients undergoing pulmonary rehabilitation experience nutritional depletion (less than $90 \%$ of ideal body weight) (Schols et al 1993). Malnutrition in COPD patients is the result of an imbalance between energy intake and energy expenditure. Reduced dietary intake in these patients has been attributed to symptoms such as postprandial dyspnea, early satiety, fatigue and loss of appetite. Elevated energy expenditure has been attributed to increased work of breathing, thermogenic effects of bronchodilators and systemic inflammation (Baarends et al 1997; Vermeeren et al 1997). The reduction in body mass index in COPD patients significantly correlates with high mortality (Landbo et al 1999). A clear influence of nutritional status on skeletal muscle contractile performance and structure has been documented in patients with anorexia nervosa (body mass index of less than 14) where maximum quadriceps muscle strength is significantly reduced and marked atrophy of type I and II muscle fibers is detectable (McLoughlin et al 1998). These patients also develop substantial reduction in limb muscle oxidative and glycolytic enzyme activities.

The respiratory muscles are not immune from the effects of malnutrition, as evidenced by a reduction in inspiratory and expiratory airway pressures in cachectic COPD patients ( $<80 \%$ of ideal body weight), as compared with normal weight COPD patients (Nishimura et al 1995). It should be emphasized that while nutritional depletion may play an important role in muscle dysfunction in COPD patients, nutritional supplementation evokes only modest improvements in muscle function, suggesting that nutritional depletion may not be the primary mechanism responsible for skeletal muscle dysfunction in COPD (Ferreira et al 2000).

\section{Medication}

Among the many drugs used to treat COPD, corticosteroids alone are capable of eliciting skeletal muscle dysfunction (steroid-induced myopathy). Short periods of high-dose corticosteroid therapy and prolonged therapy with low-dose corticosteroids are commonly prescribed for acute exacerbations of COPD and for controlling chronic symptoms in some patients. Long-term therapy with relatively high doses of corticosteroids elicits significant reduction in strength and atrophy of both ventilatory and limb muscles of COPD patients (Decramer and Stas 1992). Decramer and Stas (1992) also reported, in a study involving two patients with asthma and one with COPD, that prolonged administration of relatively high doses of corticosteroids elicits very severe reductions in quadriceps muscle strength and maximum inspiratory and expiratory pressures. Tapering of corticosteroid therapy improves quadriceps muscle force and inspiratory and expiratory muscle strengths.

In a subsequent study, Decramer and colleagues (1994, 1996) described severe quadriceps muscle weakness, out of proportion to the loss of body muscle mass, in COPD patients taking an average daily dose of steroids (4 mg of methylprednisolone) as a short-burst therapy during acute exacerbations. Depressed muscle contractility is associated with histological evidence of fiber atrophy and necrosis (Decramer et al 1996). The deleterious effects of corticosteroids on skeletal muscle function have been attributed to inhibition of signaling pathways involved in protein synthesis, as well as to augmented protein degradation, which itself is a result of increased expression and activity of the ubiquitin-proteasome pathway, including upregulation of pathway regulators known as Forkhead transcription factors. It should be noted that these studies on the influence of corticosteroid therapy on muscle function were conducted on COPD patients during acute exacerbations. To distinguish the effects of corticosteroids from other factors that may influence skeletal muscle function during acute exacerbations, Hopkinson and colleagues (2004) reported that a 2 -week course of prednisolone $(30 \mathrm{mg})$ therapy in stable COPD patients did not affect quadriceps muscle strength or metabolic parameters during exercise, suggesting that, in the absence of acute exacerbation (eg, systemic inflammation or immobility), 
short-term corticosteroid treatment does not in and of itself cause skeletal muscle weakness.

\section{Inactivity}

The fact that a great proportion of COPD patients live a sedentary lifestyle (no regular activity over a two year period) has led many investigators to attribute skeletal muscle dysfunction in these patients to physical deconditioning. Physical inactivity induces several adaptive changes in skeletal muscles, including reduced proportions of type I fibers, attenuation of oxidative enzyme capacity, regulators of mitochondrial biogenesis (PPARs and PGC-1 $\alpha$ ), fiber atrophy, reduction of antioxidant enzyme levels and lower capillary density (Franssen et al 2002; Lawler et al 2003; Remels et al 2007). These changes, collectively known as musculoskeletal deconditioning, result in significant reductions in skeletal muscle strength and endurance. The degree of musculoskeletal deconditioning is highly dependent on the causes and duration of inactivity, as well as on morphological and biochemical properties of skeletal muscles. While there are similar morphological, structural and biochemical abnormalities in the skeletal muscles of COPD patients and in those elicited by chronic inactivity, there is some evidence that physical inactivity alone does not sufficiently explain the skeletal muscle dysfunction seen in COPD patients. For instance, one study, in which proper control subjects had similar physical activity levels to those of COPD patients, revealed reductions of quadriceps muscle endurance in the COPD patients that cannot be explained by a mere lack of physical activity since reductions in the proportion of type I fibers in quadriceps muscles of COPD patients are relatively greater than in the control group (Couillard et al 2002). Indeed, while sedentary lifestyle is associated with reduction of quadriceps muscle type I fiber proportion, from $60 \%-65 \%$ in healthy active control subjects to about $40 \%$ in inactive subjects (Proctor et al 1995; Houmard et al 1998), the proportion of type I fibers in quadriceps muscles of COPD patients reaches as low as $19 \%$ (Gosker et al 2002; Allaire et al 2004; Richardson et al 2004). It is also worth noting that prolonged periods of exercise training exerts a relatively small influence on the proportion of type I fibers in quadriceps muscles of COPD patients, and only partially reverses reductions in oxidative enzyme activities (citrate synthase and 3-hydroxyacyl-CoA dehydrogenase) in the muscle (Maltais et al 1996; Whittom et al 1998).

Variant results have been published, however, regarding the precise relationship between physical activity and limb muscle endurance in COPD patients. While Serres and colleagues (1998) have described a positive correlation between quadriceps muscle endurance and physical inactivity, both Coronell and colleagues (2004) and Gosker and colleagues (2003a) have failed to find a relationship between these parameters. These contradictory results, therefore, suggest that physical inactivity may contribute to, but does not fully explain, limb muscle dysfunction in COPD patients.

\section{Age}

COPD usually develops with advanced age. Accordingly, the selective effects of aging should be taken into consideration when analyzing the various factors responsible for muscle dysfunction in these patients. It has been well established that limb muscles of older individuals are significantly smaller and have significantly more fat and connective tissues than those of younger individuals (Lexell 1995). In addition, limb muscle strength, particularly that of the quadriceps muscle, has been reported to be about 39\% lower in men in their seventies as compared to men in their twenties (Young et al 1985). Furthermore, declines in muscle strength with aging correlate with the degree of atrophy of type II fibers and are not limited to limb muscles. Indeed, maximum transdiaphragmatic pressure $\left(\mathrm{Pdi}_{\max }\right)$ measured at various lung volumes is reportedly to be approximately $25 \%$ lower in elderly subjects as compared to that measured in young subjects (Tolep et al 1995). Similarly, $13 \%$ and $23 \%$ reductions in sniff Pdi and twitch Pdi (generated by phrenic stimulation) have been observed in elderly subjects, as compared to young subjects (Polkey et al 1997). These studies clearly indicate that aging contributes to poor skeletal muscle contractile performance in COPD patients.

\section{Hypoxemia}

Many COPD patients develop chronic moderate hypoxemia or may present with repeated episodes of hypoxemia. It has been well established that prolonged exposure to hypobaric hypoxia is associated with significant reductions in skeletal muscle strength and endurance, increases in muscle atrophy and attenuation of mitochondrial Krebs cycle enzyme activity (Hoppeler et al 1990; Caquelard et al 2000). Although there is no direct proof of the involvement of hypoxemia in reduced skeletal muscle strength and endurance in COPD patients, there is circumstantial evidence that suggests that hypoxemia may contribute to the deterioration of skeletal muscle performance. For instance, the proportions of type I fibers in quadriceps muscles are significantly lower in hypoxemic COPD patients as compared to nonhypoxemic COPD patients (Gosker et al 2002). 
Moreover, exercise endurance in COPD patients correlates positively with $\mathrm{PaO}_{2}$ (Serres et al 1998). Jakobsson and colleagues (1990) have reported that adenosine triphosphate (ATP), glycogen and creatine phosphate levels in quadriceps muscle fibers are significantly reduced in COPD patients with chronic respiratory failure as compared to those without respiratory failure and they described a significant correlation between muscle metabolites and arterial $\mathrm{PO}_{2}$. Moreover, chronic hypoxemic COPD patients show greater levels of exercise-induced lipid peroxidation and oxidized proteins in their quadriceps muscles than do nonhypoxemic COPD patients (Koechlin et al 2005). As with the case of lower limb muscles, maximum diaphragm force and diaphragm endurance are both significantly reduced in COPD patients with chronic hypoxemia, although inhalation of $\mathrm{O}_{2}$ for $15 \mathrm{~min}$ elicits an increase in diaphragm strength and endurance (Zattara-Hartmann et al 1995).

Hypoxemia can elicit skeletal muscle dysfunctions through direct and indirect actions on contractile processes. The acute and direct inhibitory effects of hypoxia on skeletal muscle contractile performance have been demonstrated in several in vitro experiments utilizing rat diaphragm strips (Shee and Cameron 1990). While these experiments might explain the decline in limb muscle and diaphragm strength in severe COPD patients, the mechanisms responsible for the relationship between hypoxemia and fiber type redistribution and alterations in the metabolic profiles of skeletal muscles remain unclear. Indirect inhibitory effects of hypoxemia on skeletal muscle function are mediated mainly through the release of pro-inflammatory cytokines such as TNF $\alpha$ and IL1 $\beta$ (Ghezzi et al 1991). This notion is supported by the observations that circulating levels of TNF $\alpha$ and soluble $\mathrm{TNF} \alpha$ receptors in COPD patients are significantly higher than in control subjects and that these levels are inversely related to $\mathrm{PaO}_{2}$ (Takabatake et al 2000).

\section{Smoking}

Most COPD patients are current or previous smokers, making smoking the main risk factor for COPD. However, the potential effects of smoking on skeletal muscle function remain unclear. A recent study by Montes de Oca and colleagues (2008) suggests that smoking per se, independent of the presence of COPD, elicits skeletal muscle atrophy, as indicated by a reduction in the cross-sectional areas of both type I and II fibers, a reduction in the expression of constitutive nitric oxide synthases and augmentation of the number of low oxidative and highly glycolytic muscle fibers. The deleterious effects of smoking on muscle metabolism have been further analyzed by Petersen and colleagues (2007a), who have reported that heavy smoking ( $\geq 20$ cigarettes/day for $\geq 20$ years) elicits no change in whole body protein breakdown but significantly attenuates quadriceps muscle protein synthesis and augments the expression of both myostatin (inhibitor of muscle growth) and atrogin-1 (E3 ligase). These results suggest that smoking induces skeletal muscle fiber atrophy as a result of inhibition of protein synthesis, rather than as a result of increased protein degradation. These deleterious effects of smoking on skeletal muscle function may be mediated directly by nicotine or by other toxic byproducts of cigarette smoke, or indirectly as a result of changes in lifestyle and physical activity.

\section{Local factors}

Skeletal muscle dysfunction in COPD patients has also been attributed to local factors within skeletal muscle fibers that may elicit specific changes in protein expression and function, eventually resulting in reduction of muscle mass and depressed contractile functions. These factors include oxidative and nitrosative stress of muscle fibers and changes in the balance between protein synthesis and degradation.

\section{Oxidative and nitrosative stress}

Both ROS and RNS species are highly reactive molecules normally produced at relatively low levels inside skeletal muscle fibers. ROS are derived from superoxide anion $\left(\mathrm{O}_{2}{ }^{*}\right)$ while RNS are derived from nitric oxide (NO). In normal skeletal muscle fibers, ROS are produced at relatively low levels and play a positive role in maintaining muscle contractility (Reid 1996). However, increased production of these species, to levels significantly greater than those that can be neutralized by intracellular antioxidant defenses, leads to the development of a state of oxidative stress, which has profound effects on action potential conduction, excitation-contraction coupling, contractile proteins, and mitochondrial respiration (Reid 1996).

NO is formed from L-arginine by nitric oxide synthases (NOSs). Three distinct NOS isoforms have been identified: neuronal (nNOS) and endothelial (eNOS), which are constitutively expressed in many cell types; and inducible NOS (iNOS), which is induced by pro-inflammatory cytokines (El-Dwairi et al 1998; Stamler and Meissner 2001). In normal mammalian skeletal muscles, a special form of $\mathrm{nNOS}(\mathrm{nNOS} \mu)$ is expressed close to the sarcolemma and musculo-tendon junction (Kobzik et al 1994; Brenman et al 1995) whereas the eNOS isoform is expressed inside the mitochondria of mature muscles (Kobzik et al 1995). 
iNOS is induced inside the cytosol of skeletal muscles in septic humans and other animals and in cultured myoblasts exposed to inflammatory cytokines. Constitutive NO production inside skeletal muscle fibers modulates glucose transport and insulin-mediated skeletal muscle vasodilation (Steinberg et al 1994; Baron 1996; Balon and Nadler 1997; Kapur et al 1998; Roberts et al 1998). In addition, NO promotes vasodilation of skeletal muscle vasculature by acting directly on smooth muscles (Hussain et al 1992), whereas NO synthesized within the muscles, nNOS, promotes vasodilation of muscle vessels by inhibiting sympathetic vasoconstriction (Thomas et al 1998; Thomas and Victor 1998).

In contrast to the regulatory roles that physiological levels of ROS and RNS play inside skeletal muscle fibers, excessive levels of ROS and RNS provoke a diverse array of deleterious effects that are attributed to peroxidation of membrane phospholipids, carbonyl formation and nitration of tyrosine residues. Peroxidation of membrane lipids leads to the fragmentation of polyunsaturated fatty acids, resulting in the production of various cytotoxic and highly reactive aldehydes, alkenals, and hydroxyalkenals such as malonaldehyde (MDA) and 4-hydroxy-2-nonenal (HNE) (Halliwell and Gutteridge 1989). In comparison, carbonyls are formed as a result of oxidation of the amino acids arginine, lysine, threonine, and proline (Davies 2003). As yet, the influence of tyrosine nitration on muscles has not been fully uncovered, although it is known to adversely affect protein function and is linked to severity status of COPD in both acute and chronic situations (Montes de Oca et al 2005).

The development of oxidative and nitrosative stress has been documented in the plasma, urine and skeletal muscles of COPD patients, both at rest and following exercise. In patients with severe COPD, urinary MDA levels, and $\mathrm{H}_{2} \mathrm{O}_{2}$ concentrations in breath condensate are significantly higher than those measured in control subjects (Mercken et al 2005). In resting quadriceps muscles of patients with severe COPD, total glutathione concentrations are lower whereas the levels of HNE and lipofuscin (products of lipid peroxidation) are significantly higher than those detected in control subjects (Engelen et al 2000a; Allaire et al 2002; Barreiro et al 2003). In addition, resting limb muscles of COPD patients have increased protein tyrosine nitration and elevated levels of iNOS protein, suggesting the development of nitrosative stress (Barreiro et al 2003; Montes de Oca et al 2005). With respect to exercise, patients with moderate to severe COPD have elevated ROS-induced DNA damage in peripheral blood mononuclear cells, plasma uric acid, blood oxidized glutathione and lipid peroxides levels at the end of whole body exercise indicating that these patients experience systemic oxidative stress, even during normal daily activity (Vina et al 1996; Heunks et al 1999; Mercken et al 2005). Couillard and colleagues (2002) have proposed that exercising limb muscles might be an important source of ROS products released into the plasma of COPD patients. This is supported by observations that carbonyl formation and lipid peroxidation increase significantly in quadriceps muscles of patients with severe COPD (Couillard et al 2003).

In contrast to the amount of research using the quadriceps muscle, little information is yet available regarding alterations in the redox status of the diaphragm in COPD patients. Barriero and colleagues (2005a) were the first to report that carbonyl and HNE-protein adducts were significantly elevated in the diaphragms of patients with severe COPD (Figure 4). At the same time, these authors found no rise in protein tyrosine nitration in the diaphragms of patients with severe COPD. A more recent study by Wijnhoven and colleagues (2006) failed to detect a rise in lipid peroxidation in the diaphragms of patients with moderate and severe COPD patients. These contradictory results are likely due to the relatively low number of diaphragm samples that were examined and to differences in the methodologies that were used to evaluate oxidant and antioxidant levels. So, despite clear evidence of the development of oxidative stress in limb muscles of COPD patients, the contribution of oxidative stress to the contractile dysfunction of these muscles remains under investigation, although indirect evidence supports a strong role for oxidative stress in depressed skeletal muscle strength and endurance.

\section{Targets of ROS and RNS in skeletal muscles}

ROS and RNS influence skeletal muscle contractile performance by targeting several enzymes involved in mitochondrial respiration, glycolysis and $\mathrm{Ca}^{++}$flux. It has long been recognized that complex I, II, and IV of the mitochondrial respiratory chain are particularly sensitive to the inhibitory effects of ROS and RNS (Cleeter et al 1994; Murray et al 2003). Other targets in the mitochondria include Krebs cycle oxidative enzymes such as aconitase, which is inhibited and degraded when exposed to $\mathrm{H}_{2} \mathrm{O}_{2}$ and $\mathrm{O}_{2}{ }^{--}$(Bulteau et al 2003). Creatine kinase (CK) is another target of ROS and RNS inside quadriceps muscles of COPD patients (Barreiro et al 2005c). Others have confirmed that $\mathrm{CK}$ is sensitive to ROS generation during skeletal muscle fiber injury (Pierce et al 2007) and is also target of peroxynitrite and lipid peroxidation products (Kanski et al 2005; Eliuk et al 2007). In quadriceps muscles of COPD patients, the activity of $\mathrm{CK}$ 
A

MW (KDa)

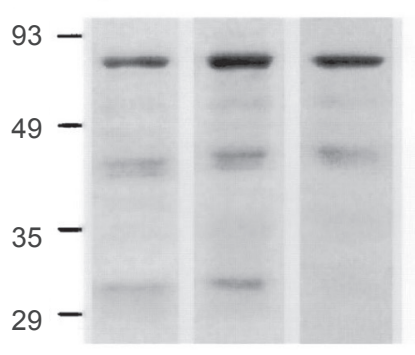

B

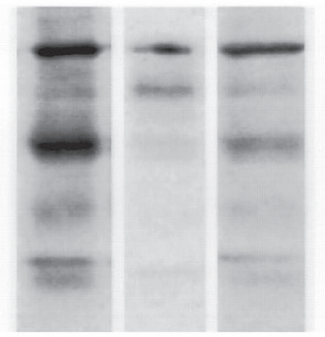

Moderate COPD
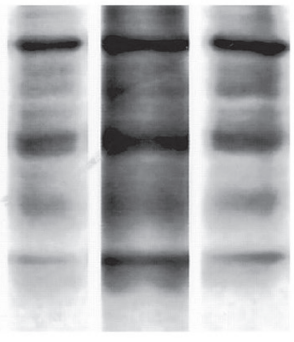

Severe COPD
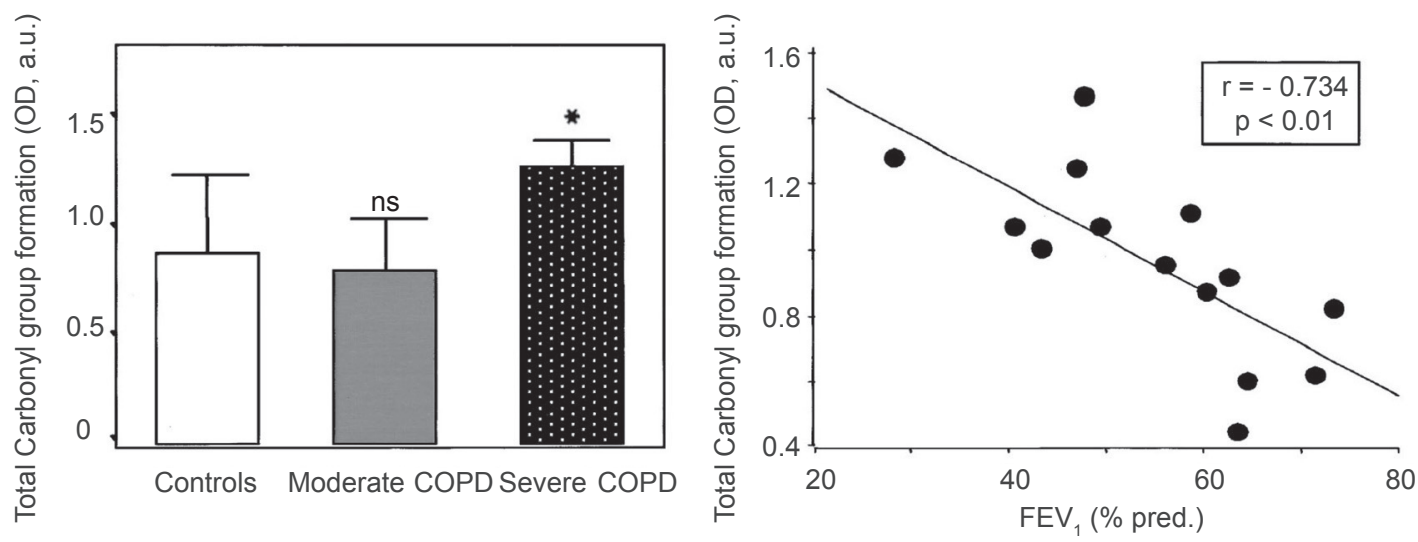

Figure 4 A) Representative examples of protein oxidation (total carbonyl groups) in diaphragms of control subjects and patients with moderate and severe COPD. B) Mean values \pm SD of total carbonyl formation higher in the patients with severe COPD, compared to control subject muscles (*p $=0.05$ ). No difference in total diaphragmatic carbonyl formation between patients with moderate COPD and control subjects (ns = nonsignificant). Among overall patients with COPD, optical densities of total carbonyl group formation significantly correlated with $\mathrm{FEV}_{1}$ (\% predicted). Note that $14 \mathrm{COPD}$ patients are depicted (two mild, six moderate, six severe) in correlation graph. Patients with moderate COPD have FEV, and FVC of $62 \pm 4$ and $72 \% \pm 11 \%$ of predicted, respectively. Patients with severe COPD have FEV and FVC of $42 \pm 7$ and $54 \% \pm 9 \%$ of predicted, respectively. Copyright (C) 2005. Adapted from Barreiro E, de la Puente B, Minguella J, et al 2005a. Oxidative stress and respiratory muscle dysfunction in severe chronic obstructive pulmonary disease. Am J Respir Crit Care Med, I7I:I I I6-24.

Abbreviations: COPD, chronic obstructive pulmonary disease; $\mathrm{FEV}_{1}$, forced expiratory volume in one second; FVC, forced vital capacity.

is inversely related to the intensity of carbonylation of this protein, suggesting that $\mathrm{CK}$ activity is inhibited in these muscles (Barreiro et al 2005c).

Enzymes involved in glycolysis are also targeted by both ROS and RNS inside skeletal muscles. These enzymes include enolase, aldolase and glyceraldehyde 3-phosphate dehydrogenase, which are strongly carbonylated, HNE-modified and tyrosine nitrated within the diaphragm (Barreiro et al 2005b; Hussain et al 2006; Vassilakopoulos et al 2007). These modifications are likely to inhibit their activities (Souza and Radi 1998; Barreiro et al 2005b; Hussain et al 2006; Vassilakopoulos et al 2007). However, whether or not the inhibitory effects of ROS and RNS on glycolytic enzymes are sufficient to alter glucose metabolism of skeletal muscle fibers remains to be investigated. Other proteins modified by ROS and RNS inside skeletal muscles include $\mathrm{Na}^{+} / \mathrm{K}^{+}$pump (Kurella et al 1995), Ca ${ }^{++}$ATPase (Viner et al 1997; Klebl et al 1999) and ryanodine receptor channels (RyR) (Sun et al 2001).
Finally, ROS and RNS might also target several myofibrillar proteins including actin, myosin heavy chain and light chain, tropomyosin, $\gamma$-actin and actinin (Milzani et al 2000; Kim et al 2002; Kanski et al 2005; Vassilakopoulos et al 2007). Modifications of these proteins by ROS and RNS lead to alterations in function, changes in $\mathrm{Ca}^{++}$and increased degradation.

\section{Molecular sources of ROS and RNS}

Although detailed mechanisms behind the development of oxidative stress in skeletal muscles of COPD patients remain under investigation, conventionally the process has been attributed to an imbalance between the rate of oxidant production and the levels of antioxidant defenses.

\section{Mitochondria}

The mitochondria are major sites of intracellular ROS production as $5 \%$ of molecular $\mathrm{O}_{2}$ is reduced to $\mathrm{O}_{2}^{-\bullet}$ as a result of electron leaks from the respiratory chain. Two findings 
suggest that mitochondrial membrane potentials might be abnormally elevated in limb muscles of COPD patients and might trigger an increase in ROS production. Sauleda and colleagues (1998) have reported that cytochrome c oxidase activity (complex IV) is significantly increased in quadriceps muscles of COPD patients with respiratory failure. However, because the expression of $12 \mathrm{~S}$ ribosomal RNA (biomarker of mitochondrial biogenesis) is also increased in these patients, it is unclear as to whether the observed rise in cytochrome c oxidase activity is due to increased mitochondrial number or genuine augmentation of cytochrome c oxidase activity in a given mitochondrion, or both. Additionally, Gosker and colleagues (2003b) and Russell and colleagues (2004) have shown that the expression of uncoupling protein 3 (UCP3, uncouples oxidative phosphorylation from mitochondrial membrane potentials) is significantly reduced in quadriceps muscles of COPD patients. Although attenuation of UCP3 is likely to trigger augmentation of mitochondrial ROS production, direct measurements of this production in limb and ventilatory muscles of COPD are clearly required to elucidate the contribution of mitochondrial sources to overall ROS production.

\section{Xanthine oxidase}

Under physiological conditions, hypoxanthine and xanthine are oxidized to uric acid by xanthine dehydrogenase, however, under hypoxic or ischemic conditions, xanthine dehydrogenase is converted to xanthine oxidase, which preferentially reduces molecular $\mathrm{O}_{2}$ to $\mathrm{O}_{2}^{-\bullet}$ and $\mathrm{H}_{2} \mathrm{O}_{2}$ (Engerson et al 1987). During exercise, both hypoxia and increased levels of xanthine and hypoxanthine inside skeletal muscle fibers cause significant elevation of xanthine oxidase activity. As in the case of mitochondrial ROS production, little direct evidence of increased xanthine oxidase in skeletal muscles of COPD has been published thus far, although Heunks and colleagues (1999) have reported that pre-treatment with the xanthine oxidase inhibitor allopurinol significantly attenuates exercise-induced elevation of plasma oxidized glutathione and MDA levels in patients with COPD who have performed incremental exercise. Whether or not allopurinol treatment attenuates oxidative stress inside muscle fibers of exercising muscles remains unclear.

\section{NADPH oxidase}

NADPH oxidase is an enzyme complex first described in phagocytes, where it consists of four essential subunits

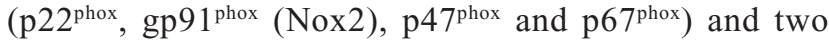
additional subunits (p40 phox and Rac2). NADPH oxidase is also expressed in nonphagocytes where it produces ROS under basal conditions but, upon stimulation, ROS are produced intracellularly at much lower levels than they are in phagocytes. Recent studies have confirmed the presence of Nox2, p4 $7^{\text {phox }}$, p $67^{\text {phox }}$ and $\mathrm{p} 22^{\text {phox }}$ subunits in skeletal muscle samples and have implicated these subunits in the regulation of $\mathrm{Ca}^{++}$influx and insulin signaling (Hidalgo et al 2006; Javeshghani et al 2002; Espinosa et al 2006; Wei et al 2006). These studies clearly suggest that NADPH oxidase-derived ROS play important physiological roles in regulating skeletal muscle signaling. On the basis of these results, one would not expect that a mild to moderate augmentation of musclederived NAPDH oxidase activity would contribute to the development of oxidative stress in skeletal muscles of COPD patients. In comparison, neutrophil- and macrophage-derived NADPH oxidases are more likely to generate pathological levels of ROS that elicit oxidative stresses in skeletal muscles. However, there is little evidence that significant neutrophil and macrophage infiltration develops in skeletal muscles of COPD patients. In fact, normal numbers of inflammatory cells have been detected in the vastus lateralis muscles of patients with COPD (Gosker et al 2003a).

\section{Nitric oxide synthases}

Muscle redox state is strongly influenced by NO production, since increased NO levels in the presence of enhanced $\mathrm{O}_{2}^{-\bullet}$ levels leads to the production of the highly reactive peroxynitrite. Few studies have as yet explored whether or not NO production and NOS expression are altered in skeletal muscles of COPD patients. Several studies have reported that the levels of nNOS and eNOS proteins in quadriceps of patients with severe and moderate COPD are similar or even lower than that those of control subjects (Barreiro et al 2003, 2008a; Montes de Oca et al 2005). In comparison, others described induction of the iNOS isoform in quadriceps of patients with severe COPD patients, particularly those with low BMI (Agusti et al 2004; Montes de Oca et al 2005; Barreiro et al 2008a). In addition, elevated protein tyrosine nitration in quadriceps muscles of COPD patients has been documented by many authors thereby confirming an increase in peroxynitrite formation in these patients (Barreiro et al 2003; Agusti et al 2004; Montes de Oca et al 2005). It is worth noting that not all skeletal muscles of COPD patients show evidence of nitrosative stress and peroxynitrite formation. For instance, Barreiro and colleagues (2005a) found no significant differences in protein tyrosine nitration, despite the presence of elevated protein carbonylation and 4HNE-protein adduction formation, in the diaphragms of patients with 
moderate and severe COPD. In fact, the production of NO in the diaphragms of these patients might have been even lower than in normal subjects, as indicated by the presence of lower eNOS protein levels (Barreiro et al 2005a). Thus, while oxidative stress develops in the diaphragms of patients with COPD, there is little evidence that nitrosative stress also develops in that muscle.

The development of oxidative stress in skeletal muscles of COPD patients has also been attributed to reduction in antioxidant capacity. Early reports suggest that plasma levels of nonenzymatic antioxidants are significantly lower in COPD patients, both at rest and after localized exercise, than they are in control subjects (Rahman et al 1996; Couillard et al 2002). Measurements of protein levels and activities of antioxidant enzymes reveal that in patients with severe COPD patients and significant muscle wasting, Mn-SOD and glutathioneS-transferase activities in resting quadriceps muscles are significantly elevated (Gosker et al 2005; Barreiro et al 2008a). However, the levels of Mn-SOD, catalase, heme oxygenase-1 and glutathione peroxidase (an important enzyme in the metabolism of glutathione) in the quadriceps muscles and diaphragms of patients with moderate COPD are not different from control subjects (Couillard et al 2003; Barreiro et al 2003, 2005a, 2008a).

Despite similarities in antioxidant enzyme levels, the response of these enzymes to increased oxidant production elicited by exercise or exercise training appears to be abnormal. Indeed, Couillard and colleagues (2003) have reported that glutathione peroxide activity in quadriceps muscles of patients with moderate COPD remains unchanged from resting values following localized quadriceps muscle endurance exercise, while the activity of the same enzyme rises significantly in control subjects. A similar lack of augmentation of Mn-SOD activity in response to endurance training of quadriceps muscles has been observed in patients with moderate COPD (Barreiro et al 2008a). These results suggest that exercise-induced oxidative stress does indeed develop in limb muscles of COPD patients, in part as a result of an inability of antioxidant enzymes to respond to increased oxidant production.

\section{Regulation of protein synthesis/ degradation}

Regulation of muscle mass is a dynamic process involving a delicate balance between hypertrophic (protein synthesis) and atrophic (degradation) signalling pathways. There are four classes of proteolytic enzymes that are involved in protein degradation inside skeletal muscles. In different models of muscle wasting there is coordinated stimulation of these systems, which include the proteasomal and the lysosomal pathways, calpains and caspases. Proteins targeted for degradation go through several steps, the first of which involves the activation of ubiquitin by E1 ubiquitinactivating proteins and then a transfer of activated ubiquitin to E2 ubiquitin conjugating enzymes and, finally, eventual transfer of ubiquitin to the targeted proteins. Two musclespecific E3 ligases, namely, muscle ring finger (MuRF1) and muscle atrophy F-box (MAFbx or atrogin-1) have recently been cloned and have been shown to be significantly induced inside muscle fibers in various models of muscle atrophy, including denervation, immobilization and fasting (Bodine et al 2001). Upstream signals that mediate the activation of the ubiquitin-proteasome pathway in skeletal muscle atrophy remain unclear. However, recent studies have indicated that expressions of atrogin-1 and MuRF1 are controlled by a complex signaling network comprised of the FoxO transcription factors (Sandri et al 2004) and their upstream regulators, including protein kinase B (AKT) (Cai et al 2004).

The second step involves the lysosomal system, which consists of several cathepsins (acid hydrolases), glycosidases, lipases, nucleases and phosphatases, and is responsible for degradation, through autophagy, of most membrane and extracellular proteins taken up by endocytosis, in addition to cytoplasmic proteins and organelles (Scott and Klionsky 1998). Calpains consist of fourteen different cysteine proteases that are dependent on $\mathrm{Ca}^{++}$. Skeletal muscles contain substantial levels of two ubiquitous calpains, one that requires micromolar concentrations of $\mathrm{Ca}^{++}$( $\mu$-calpain), and one that requires millimolar levels of $\mathrm{Ca}^{++}$(m-calpain), in addition to the calpain inhibitor calpstatin (Bartoli and Richard 2005). Calpains cleave proteins at selective sites and are not involved in the degradation of cytosolic proteins inside skeletal muscles. Finally, caspases are responsible for degrading cellular proteins during apoptosis and many recent reports have documented increases in caspase activity and/or expression inside skeletal muscles in a variety of pathological conditions, including muscular dystrophy, sepsis and exercise-induced oxidative stress (Supinski and Callahan 2006; Huey et al 2008; Kocturk et al 2008). Although it is known that caspase- 3 acts upstream from the proteasomal pathway and that it is capable of degrading actin in in vitro settings (Du et al 2004), the exact contributions of caspases to in vivo skeletal muscle protein degradation remain unclear.

It is generally assumed that peripheral muscle atrophy in patients with COPD is due to an imbalance between protein synthesis and degradation, in favor of the latter 
(Debigare et al 2001). However, the precise contributions of each step of the proteolysis pathway to peripheral muscle atrophy in COPD patients remains unclear. Debigare and colleagues (2003b) have shown that limb muscle atrophy in COPD patients may be due to an increase in the ratio of catabolic factors (IL6 and cortisol) to anabolic factors (testosterone, dehydroepiandrosterone and insulin-like growth factor-1 [IGF-I]). Increased IL6, ROS and RNS levels are expected to upregulate the ubiquitin-proteasome components, while increased anabolic factors are expected to downregulate these components. In a very recent study, Debigare and colleagues (2008) employed microarray technology to compare gene expression profiles in quadriceps muscles of four patients with moderate or severe COPD to those of control subjects. They reported significant upregulation of FoxO1 and FoxO3 transcription factors in quadriceps muscles of COPD patients. Both transcription factors promote muscle atrophy through inhibition of IGF-I-mediated muscle growth and by upregulating the expression of atrogin-1 and MuRF-1 (Sandri et al 2004; Stitt et al 2004). In another study, Doucet and colleagues (2007) confirmed that FoxO1 mRNA and protein and atrogin-1 and MuRF-1 mRNA expressions are significantly upregulated in quadriceps muscles of COPD patients, suggesting that the activity of the proteasomal pathway is enhanced in limb muscles of these patients (Figure 5). This observation cannot be explained by removal of the inhibitory effect of protein kinase $\mathrm{B}$ (AKT) on FoxO1 activity since AKT activity is significantly greater in quadriceps muscles of COPD patients than it is in control subjects (Doucet et al 2007). It is possible that observed upregulations of FoxO1, atrogin-1 and MuRF-1 levels are due to increased activity of NFKB transcription, which is known to positively modulate the proteasomal pathway inside skeletal muscle (Cai et al 2004).

Activation of the ubiquitin-proteasomal pathway is not limited to the limb muscles of COPD patients. Activity of the $20 \mathrm{~S}$ proteasome and atrogin- 1 expression have recently been shown to be upregulated by 3 -fold in the diaphragms of patients with mild to moderate COPD (Ottenheijm et al 2006b). While these studies imply that the proteasomal pathway contributes to proteolysis of skeletal muscle proteins in COPD patients, no information is as yet available about the relative contributions of the lysosomal, calpain and caspase pathways to the atrophy process. Systematic and thorough investigations of how, where, and when these pathways are activated, and thus contribute to muscle protein degradation, are clearly needed in relation to patients with COPD.

To further explore the functional importance of FoxO transcription factors in regulating muscle protein degradation in COPD patients, for the present study the dataset of Debigare and colleagues (2008) was analyzed using Ingenuity Pathway Analysis software (http://www.ingenuity. $\mathrm{com} /$ ) to show that three major networks link the majority of significantly regulated genes in the quadriceps muscles of COPD patients. Figure 6 shows the top network uncovered by this analysis. This network contains several highly connected nodes, such as FoxO1 and FoxO3, as well as NFkB transcription factors and two signaling pathways related to mitogen activated protein kinases, namely, the Erk1/2 and p38 pathways. Network analysis suggests that elevated expression and/or activation of FoxO1, FoxO3 and $\mathrm{NF \kappa B}$ transcription factors in quadriceps muscles of COPD patients might be due to both abnormalities in the insulin pathway and attenuation of FHL2 expression.

FHL2 (four-and-a-half LIM only protein 2) is a member of a family of proteins containing the LIM domain, a conserved cysteine-rich module that plays several important roles as an adaptor or as a scaffold to support the assembly of multimeric protein complexes (Johannessen et al 2006). In skeletal muscles, FHL2 promotes differentiation of myoblasts into myotubes (Martin et al 2002) and functions as an adaptor molecule that links the metabolic enzymes creatine kinase, adenylate cyclase and phosphofructokinase to titin, a protein that plays a crucial role as organizer of the sarcomere (Lange et al 2002). In addition, FHL2 directly interacts with FoxO1 and suppresses its transcriptional activity (Yang et al 2005). Furthermore, deletion of FHL2 augments TRAF6-dependent NF $\kappa B$ activity, suggesting that a role of FHL2 is to attenuate NF $\kappa$ B activity (Bai et al 2005). The fact that FHL2 expression is significantly downregulated in quadriceps muscles of COPD patients raises the possibility that the increased activities of FoxO1, FoxO3 and NFKB transcription factors might be due to attenuation of the inhibitory effects of FHL2 on the activity and/or expression of these factors (Debigare et al 2008). This network analysis also suggests that FoxO1 and FoxO3 transcription factors may be involved in regulating the expression of UCP2 and troponin C in muscles in these patients (Figure 6). Clearly, additional studies are required to fully elucidate the functional roles, not only of FoxO and $\mathrm{NF} \kappa \mathrm{B}$ transcription factors, but also of all factors related to the FHL2 and insulin pathways in mediating skeletal muscle dysfunction.

\section{Vascular density and capillarization}

Little information is available about changes in capillary density in skeletal muscles of COPD patients. An initial study by Jobin and colleagues confirmed that capillary to 

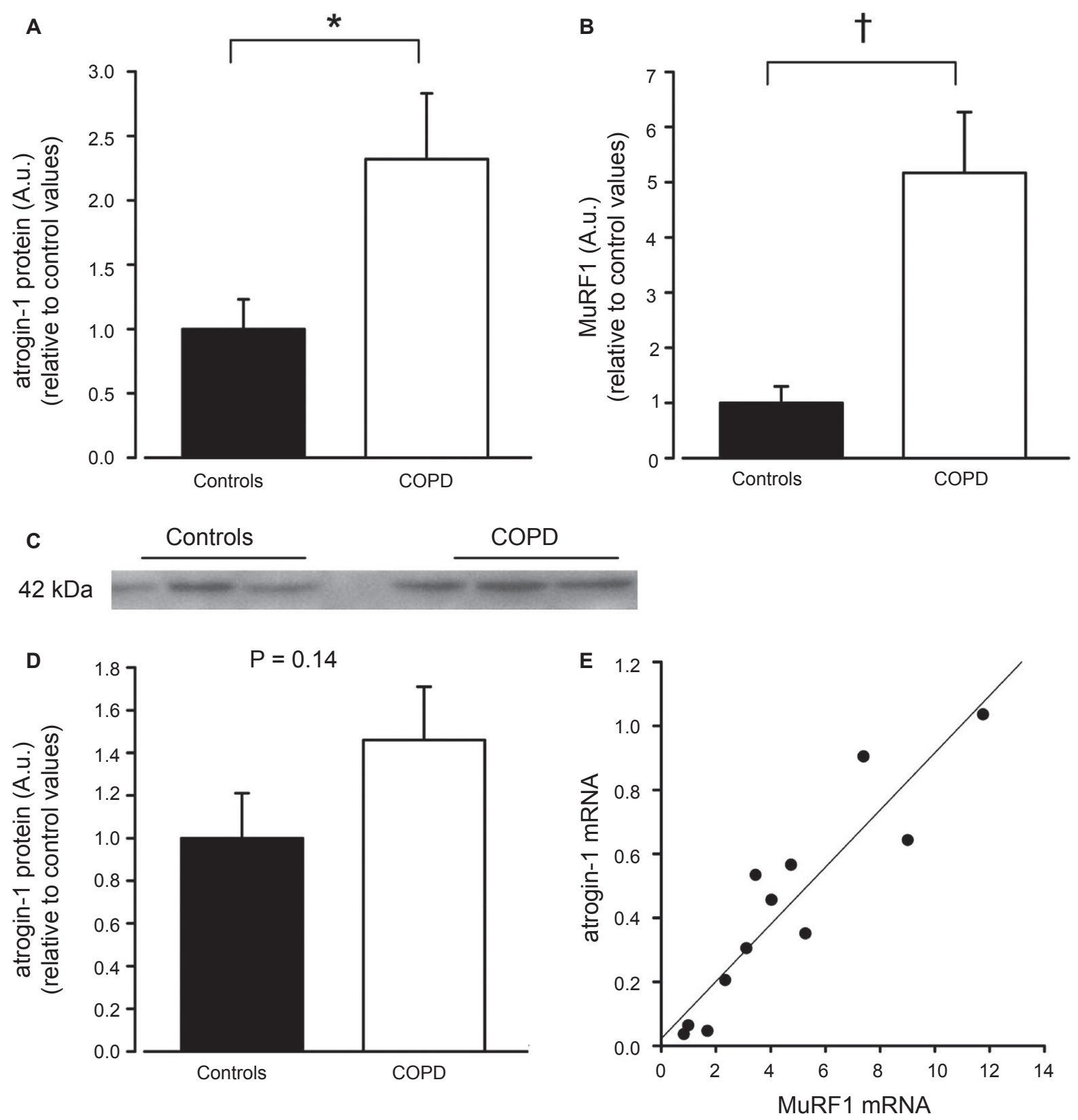

Figure 5 A) Atrogin-I mRNA expression; B) MuRFI mRNA expression; C) representative Western blot for atrogin-I; D) atrogin-I protein expression, all from quadriceps muscles of control subjects and COPD patients. Expression data relative to control values and presented in AU. mRNA data normalized for RPLPO, cytoplasmic protein contents normalized for $\alpha$-tubulin. E) Significant correlation between atrogin-I and MuRFI mRNA expressions $(r 2=0.84 ; p<0.00 I)$ in COPD patients. Values are mean \pm SEM; ${ }^{*} \mathrm{p}<0.05 ;{ }^{+} \mathrm{p}<0.001$. Copyright $@ 2$ 2007. Adapted from Doucet M, Russell AP, Leger B, et al 2007. Muscle atrophy and hypertrophy signaling in patients with chronic obstructive pulmonary disease. Am J Respir Crit Care Med, I76:26I-9.

Abbreviations: AU, atomic units; COPD, chronic obstructive pulmonary disease; MuRFI, muscle-specific RING finger protein I; mRNA, messenger ribonucleic acid; RPLPO, large ribosomal protein; SEM, standard error of mean.

muscle fiber ratios in the vastus lateralis muscle of patients with severe COPD are about $47 \%$ lower than those measured in the same muscle of age-matched control subjects (Jobin et al 1998). A subsequent study by the same group reported relatively smaller reductions in the capillary to fiber ratio in the muscles of patients with mild to moderate COPD (Whittom et al 1998). Reduction in capillary density is thought to have a deleterious effect on muscle oxidative capacity. This is indeed the case in limb muscles of COPD patients, where the activities of citrate synthase and 3-hydroxyacyl coenzyme A dehydrogenase (markers of oxidative capacity) are significantly reduced (Maltais et al 2000). The decline in the activity of citrate synthase is proportional to the deterioration of functional status of 


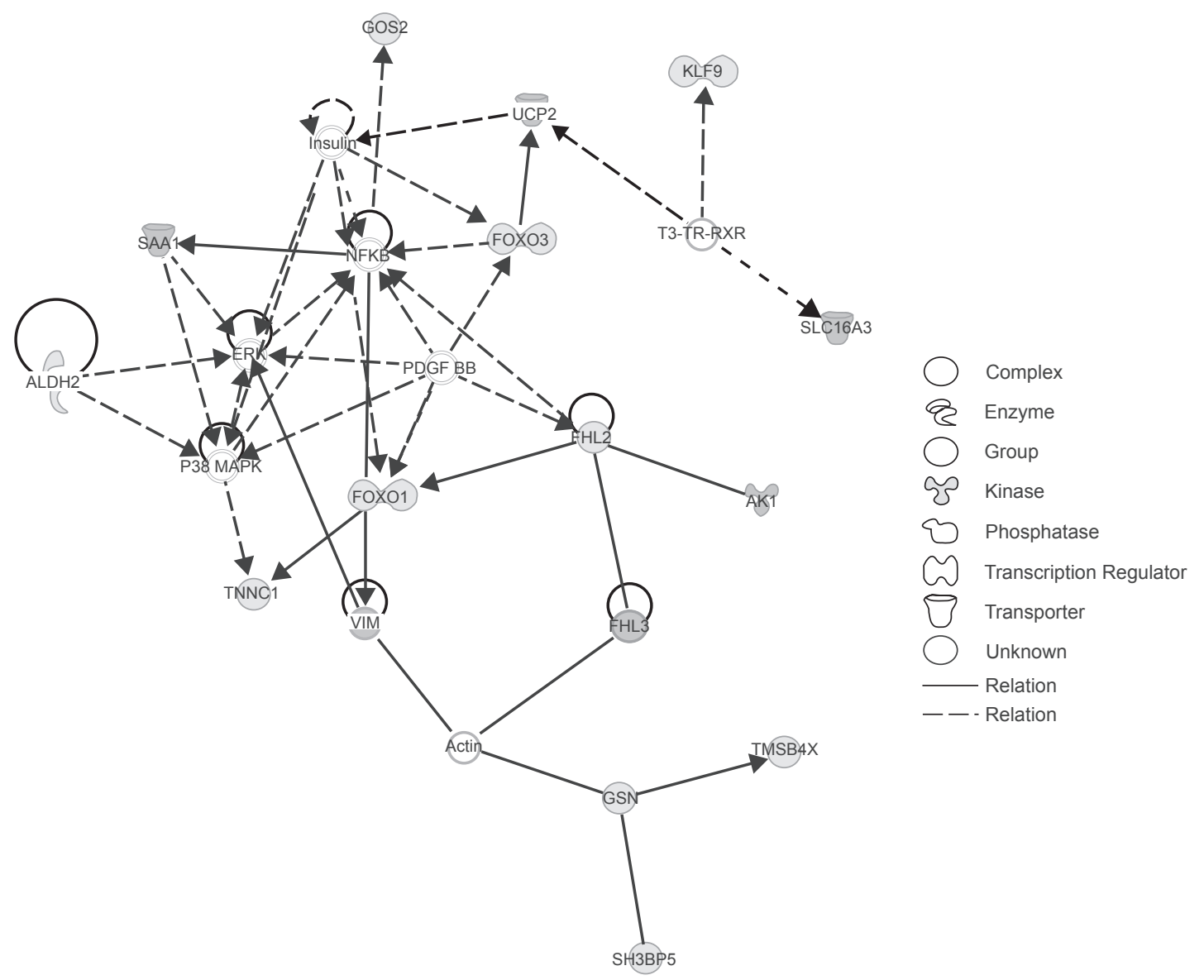

Figure 6 Top network of upregulated genes in quadriceps muscles of COPD patients, compared with control subjects. Figure created with Ingenuity Pathway Analysis System of microarray data from Debigare and colleagues (2008). Microarray data set used as an input file with RMA (robust multiarray analysis) threshold of I.2 to specify upregulated genes. Filled nodes indicate upregulated genes in COPD patients. Empty nodes designate genes not detected by microarray data. Straight lines indicate direct relation while interrupted lines suggest indirect interactions.

Abbreviations: AKI, adenylate kinase I;ALDH2, aldehyde dehydrogenase 2 family, mitochondrial; COPD, chronic obstructive pulmonary disease; ERK, extracellular signalregulated kinase; FHL2, four and half LIM domains 2; FHL3, cysteine and glycine-rich protein 3; FOXOI, forkhead box OIA (FKHR); FOXO3, forkhead box O3A (FKHRLI); FOX06, forkhead box 06; G0S2, putative lymphocyte G0/GI switch gene; KLF9, Kruppel-like factor 9; NFKB, nuclear factor of kappa light polypeptide; P38MAPK, p38 mitogenactivated protein kinase; PDGF-BB, platelet-derived growth factor BB; SAAI, serum amyloid AI;SLCI6A3, solute carrier family 16 (monocarboxylic acid transporters), member 3;T3-TR-RXR, T3-thyroid hormone receptor-retinoid X receptor complex;TMSB4X, thymosin beta 4, X-linked;TNNCI, slow troponin C;VIM, vimentin; UCP2, uncoupling protein 2, mitochondrial, proton carrier.

the muscle (Maltais et al 2000). However, because total muscle mitochondrial density is significantly reduced in COPD patients (Gosker et al 2007a), it is unclear whether or not the observed reduction in oxidative enzyme capacity is due to attenuation of total mitochondrial number and/or to specific defects in the activity of these enzymes. It should be emphasized that reduction in skeletal muscle mitochondrial density in COPD patients is muscle-specific; it has been described in the vastus lateralis muscle but not in the tibialis muscle (Gosker et al 2007a). Attenuation of capillary and mitochondrial densities in skeletal muscles of COPD patients is associated with augmentation of serum and muscle lactic acid levels during exercise and an early onset of contractile fatigue (Maltais et al 1996; Engelen et al 2000b).
The precise mechanisms behind reduction in capillary density in limb muscles of COPD patients are not clear. Very recently, Barreiro and colleagues (2008b) have reported that vascular endothelial growth factors (VEGF) protein levels in the vastus lateralis of patients with moderate and severe COPD are significantly lower than those of control subjects. These observed reductions in VEGF levels cannot be explained by inactivity or fiber type switching since no relationship was found between VEGF muscle levels and exercise tolerance parameters or fiber type distribution (Barreiro et al 2008b). Expression of VEGF in the vastus lateralis muscles of COPD patients contrasts with that expressed in the diaphragm, which shows mildly, but significantly, elevated VEGF levels in patients with moderate COPD (Alexopoulou et al 2005). It should be noted that upregulation of VEGF 
expression in the diaphragms of COPD patients, which is not paralleled by an increase in fibroblast growth factor-1 and TGF $\beta$ expressions, cannot be attributed to increased mechanical loads in these patients, although other local factors such as fiber type remodeling and hypoxemia may be involved. The involvement of pro- and anti-angiogenesis factors other than VEGF in the regulation of skeletal muscle capillary density in COPD patients remains to be explored.

\section{Summary}

In this review, we have collected evidence indicating that both strength and endurance of skeletal muscles in general, and limb muscles in particular, are reduced in patients with COPD and that these abnormalities are associated with attenuated exercise capacity and increased mortality. Examinations of muscle biopsies in COPD patients reveals that lower limb muscles in particular undergo specific structural and functional alterations that are similar, but not identical, to those found in muscles that are atrophied as a result of denervation or disuse. More recent studies support the notion that, in addition to disuse/de-conditioning-induced atrophy, skeletal muscle dysfunctions in COPD patients might be due to myopathy triggered by systemic factors, including inflammation, nutritional depletion, corticosteroid use, chronic inactivity, age, hypoxemia, and smoking, and local factors due to selective increases in reactive oxygen and nitrogen species production, enhanced proteolysis, and changes in vascularization. Further studies are required to identify the precise molecular mechanisms responsible for skeletal muscle dysfunction in COPD patients.

\section{Disclosure}

The authors report no conflicts of interest in this work.

\section{References}

Agusti A, Morla M, Sauleda J, et al. 2004. NF-kappaB activation and iNOS upregulation in skeletal muscle of patients with COPD and low body weight. Thorax, 59:483-7.

Agusti AG, Sauleda J, Miralles C, et al. 2002. Skeletal muscle apoptosis and weight loss in chronic obstructive pulmonary disease. Am J Respir Crit Care Med, 166:485-9.

Alexopoulou C, Mitrouska I, Arvanitis D, et al. 2005. Vascular-specific growth factor mRNA levels in the human diaphragm. Respiration, $72: 636-41$.

Allaire J, Maltais F, Doyon JF, et al. 2004. Peripheral muscle endurance and the oxidative profile of the quadriceps in patients with COPD. Thorax, 59:673-8.

Allaire J, Maltais F, LeBlanc P, et al. 2002. Lipofuscin accumulation in the vastus lateralis muscle in patients with chronic obstructive pulmonary disease. Muscle Nerve, 25:383-9.

Baarends EM, Schols AM, Westerterp KR, et al. 1997. Total daily energy expenditure relative to resting energy expenditure in clinically stable patients with COPD. Thorax, 52:780-5.
Bai S, Kitaura H, Zhao H, et al. 2005. FHL2 inhibits the activated osteoclast in a TRAF6-dependent manner . J Clin Invest, 115:2742-51.

Balon TW, Nadler JL. 1997. Evidence that nitric oxide increases glucose transport in skeletal muscle. J Appl Physiol, 82:359-63.

Baron AD. 1996. The coupling of glucose metabolism and perfusion in human skeletal muscle. The potential role of endothelium-derived nitric oxide. Diabetes, 45(Suppl 1):S105-9.

Barreiro E, de la Puente B, Minguella J, et al. 2005a. Oxidative stress and respiratory muscle dysfunction in severe chronic obstructive pulmonary disease. Am J Respir Crit Care Med, 171:1116-24.

Barreiro E, Gea J, Corominas JM, et al. 2003. Nitric oxide synthases and protein oxidation in the quadriceps femoris of patients with chronic obstructive pulmonary disease. Am J Respir Cell Mol Biol, 29:771-8.

Barreiro E, Gea J, Di Falco M, et al. 2005b. Protein carbonyl formation in the diaphragm. Am J Respir Cell Mol Biol, 32:9-17.

Barreiro E, Gea J, Matar G, et al. 2005c. Expression and carbonylation of creatine kinase in the quadriceps femoris muscles of patients with chronic obstructive pulmonary disease. Am J Respir Cell Mol Biol, 33:636-42.

Barreiro E, Rabinovich R, Marin-Corral J, et al. 2008a. Chronic endurance exercise induces quadriceps nitrosative stress in severe COPD patients. Thorax, Oct 3 [Epub ahead of print].

Barreiro E, Schols AM, Polkey MI, et al. 2008b. Cytokine profile in quadriceps muscles of patients with severe COPD. Thorax, 63:100-7.

Bartoli M, Richard I. 2005. Calpains in muscle wasting. Int J Biochem Cell Biol, 37:2115-33.

Bellemare F, Grassino A. 1983. Force reserve of the diaphragm in patients with chronic obstructive pulmonary disease. $J$ Appl Physiol, 55:8-15.

Bernard S, LeBlanc P, Whittom F, et al. 1998. Peripheral muscle weakness in patients with chronic obstructive pulmonary disease. Am J Respir Crit Care Med, 158:629-34.

Bodine SC, Stitt TN, Gonzalez M, et al. 2001. Akt/mTOR pathway is a crucial regulator of skeletal muscle hypertrophy and can prevent muscle atrophy in vivo. Nat Cell Biol, 3:1014-9.

Brenman JE, Chao DS, Xia H, et al. 1995. Nitric oxide synthase complexed with dystrophin and absent from skeletal muscle sarcolemma in Duchenne muscle dystrophy. Cell, 82:743-52.

Broekhuizen R, Wouters EF, Creutzberg EC, et al. 2006. Raised CRP levels mark metabolic and functional impairment in advanced COPD. Thorax, 61:17-22.

Bulteau AL, Ikeda-Saito M, Szweda LI. 2003. Redox-dependent modulation of aconitase activity in intact mitochondria. Biochemistry, 42:14846-55.

Cai D, Frantz JD, Tawa NE Jr, et al. 2004. IKKbeta/NF-kappaB activation causes severe muscle wasting in mice. Cell, 119:285-98.

Caquelard F, Burnet H, Tagliarini F, et al. 2000. Effects of prolonged hypobaric hypoxia on human skeletal muscle function and electromyographic events. Clin Sci (Lond), 98:329-37.

Carbo N, Busquets S, van RM, et al. 2002. TNF-alpha is involved in activating DNA fragmentation in skeletal muscle. Br J Cancer, 86:1012-6.

Casadevall C, Coronell C, Ramirez-Sarmiento AL, et al. 2007. Upregulation of pro-inflammatory cytokines in the intercostal muscles of COPD patients. Eur Respir J, 30:701-7.

Cleeter MW, Cooper JM, Darley-Usmar VM, et al. 1994. Reversible inhibition of cytochrome c oxidase, the terminal enzyme of the mitochondrial respiratory chain, by nitric oxide. Implications for neurodegenerative diseases. FEBS Lett, 345:50-4.

Coronell C, Orozco-Levi M, Mendez R, et al. 2004. Relevance of assessing quadriceps endurance in patients with COPD. Eur Respir J, 24:129-36.

Couillard A, Koechlin C, Cristol JP, et al. 2002. Evidence of local exerciseinduced systemic oxidative stress in chronic obstructive pulmonary disease patients. Eur Respir J, 20:1123-9.

Couillard A, Maltais F, Saey D, et al. 2003. Exercise-induced quadriceps oxidative stress and peripheral muscle dysfunction in COPD patients. Am J Respir Crit Care Med, 167:1664-9. 
Crul T, Spruit MA, Gayan-Ramirez G, et al. 2007. Markers of inflammation and disuse in vastus lateralis of chronic obstructive pulmonary disease patients. Eur J Clin Invest, 37:897-904.

Davies MJ. 2003. Singlet oxygen-mediated damage to proteins and its consequences. Biochem Biophys Res Commun, 305:761-70.

Debigare R, Cote $\mathrm{CH}$, Hould FS, et al. 2003a. In vitro and in vivo contractile properties of the vastus lateralis muscle in males with COPD. Eur Respir J, 21:273-8.

Debigare R, Cote CH, Maltais F. 2001. Peripheral muscle wasting in chronic obstructive pulmonary disease. Clinical relevance and mechanisms. $\mathrm{Am}$ J Respir Crit Care Med, 164:1712-7.

Debigare R, Maltais F, Cote CH, et al. 2008. Profiling of mRNA expression in quadriceps of patients with COPD and muscle wasting. COPD, 5:75-84.

Debigare R, Marquis K, Cote CH, et al. 2003b. Catabolic/anabolic balance and muscle wasting in patients with COPD. Chest, 124:83-9.

Decramer M, de Bock, V, Dom R. 1996. Functional and histologic picture of steroid-induced myopathy in chronic obstructive pulmonary disease. Am J Respir Crit Care Med, 153:1958-64.

Decramer M, Gosselink R, Troosters T, et al. 1997. Muscle weakness is related to utilization of health care resources in COPD patients. Eur Respir J, 10:417-23.

Decramer M, Lacquet LM, Fagard R, et al. 1994. Corticosteroids contribute to muscle weakness in chronic airflow obstruction. Am J Respir Crit Care Med, 150:11-6.

Decramer M, Stas KJ. 1992. Corticosteroid-induced myopathy involving respiratory muscles in patients with chronic obstructive pulmonary disease or asthma. Am Rev Respir Dis, 146:800-2.

Dentener MA, Creutzberg EC, Schols AM, et al. 2001. Systemic anti-inflammatory mediators in COPD: increase in soluble interleukin 1 receptor II during treatment of exacerbations. Thorax, 56:721-6.

Doucet M, Russell AP, Leger B, et al. 2007. Muscle atrophy and hypertrophy signaling in patients with chronic obstructive pulmonary disease. Am J Respir Crit Care Med, 176:261-9.

Du J, Wang X, Miereles C, et al. 2004. Activation of caspase-3 is an initial step triggering accelerated muscle proteolysis in catabolic conditions. $J$ Clin Invest, 113:115-23.

El-Dwairi Q, Comtois A, Guo Y, et al. 1998. Endotoxin-induced skeletal muscle contractile dysfunction: contribution of nitric oxide synthases. Am J Physiol (Cell Physiol), 274:C770-C779.

Eliuk SM, Renfrow MB, Shonsey EM, et al. 2007. Active site modifications of the brain isoform of creatine kinase by 4-hydroxy-2-nonenal correlate with reduced enzyme activity: mapping of modified sites by Fourier transform-ion cyclotron resonance mass spectrometry. Chem Res Toxicol, 20:1260-8.

Engelen MP, Schols AM, Does JD, et al. 2000a. Altered glutamate metabolism is associated with reduced muscle glutathione levels in patients with emphysema. Am J Respir Crit Care Med, 161:98-103.

Engelen MP, Schols AM, Does JD, et al. 2000b. Exercise-induced lactate increase in relation to muscle substrates in patients with chronic obstructive pulmonary disease. Am J Respir Crit Care Med, 162:1697-704

Engelen MP, Schols AM, Does JD, et al. 2000c. Skeletal muscle weakness is associated with wasting of extremity fat-free mass but not with airflow obstruction in patients with chronic obstructive pulmonary disease. $\mathrm{Am}$ J Clin Nutr, 71:733-8.

Engerson TD, McKelvey TG, Rhyne DB, et al. 1987. Conversion of xanthine dehydrogenase to oxidase in ischemic rat tissues. $J$ Clin Invest, 79:1564-70.

Espinosa A, Leiva A, Pena M, et al. 2006. Myotube depolarization generates reactive oxygen species through $\mathrm{NAD}(\mathrm{P}) \mathrm{H}$ oxidase; ROS-elicited $\mathrm{Ca} 2+$ stimulates ERK, CREB, early genes. J Cell Physiol, 209:379-88.

Ferreira IM, Brooks D, Lacasse Y, et al. 2000. Nutritional support for individuals with COPD: a meta-analysis. Chest, 117:672-8.

Franssen FM, Broekhuizen R, Janssen PP, et al. 2005. Limb muscle dysfunction in COPD: effects of muscle wasting and exercise training. Med Sci Sports Exerc, 37:2-9.
Franssen FM, Wouters EF, Schols AM. 2002. The contribution of starvation, deconditioning and ageing to the observed alterations in peripheral skeletal muscle in chronic organ diseases. Clin Nutr, 21:1-14.

Gan WQ, Man SF, Senthilselvan A, et al. 2004. Association between chronic obstructive pulmonary disease and systemic inflammation: a systematic review and a meta-analysis. Thorax, 59:574-80.

Gea JG, Pasto M, Carmona MA, et al. 2001. Metabolic characteristics of the deltoid muscle in patients with chronic obstructive pulmonary disease. Eur Respir J, 17:939-45.

Ghezzi P, Dinarello CA, Bianchi M, et al. 1991. Hypoxia increases production of interleukin-1 and tumor necrosis factor by human mononuclear cells. Cytokine, 3:189-94.

Gosker HR, Bast A, Haenen GR, et al. 2005. Altered antioxidant status in peripheral skeletal muscle of patients with COPD. Respir Med, 99:118-25.

Gosker HR, Hesselink MK, Duimel H, et al. 2007a. Reduced mitochondrial density in the vastus lateralis muscle of patients with COPD. Eur Respir J, 30:73-9.

Gosker HR, Kubat B, Schaart G, et al. 2003a. Myopathological features in skeletal muscle of patients with chronic obstructive pulmonary disease. Eur Respir J, 22:280-5.

Gosker HR, Schrauwen P, Hesselink MK, et al. 2003b. Uncoupling protein3 content is decreased in peripheral skeletal muscle of patients with COPD. Eur Respir J, 22:88-93.

Gosker HR, van MH, van Dijk PJ, et al. 2002. Skeletal muscle fibre-type shifting and metabolic profile in patients with chronic obstructive pulmonary disease. Eur Respir J, 19:617-25.

Gosker HR, Zeegers MP, Wouters EF, et al. 2007b. Muscle fibre type shifting in the vastus lateralis of patients with COPD is associated with disease severity: a systematic review and meta-analysis. Thorax, 62:944-9.

Gosselink R, Troosters T, Decramer M. 2000. Distribution of muscle weakness in patients with stable chronic obstructive pulmonary disease. J Cardiopulm Rehabil, 20:353-60.

Gosselink R, Troosters T, Decramer M. 1996. Peripheral muscle weakness contributes to exercise limitation in COPD. Am J Respir Crit Care Med, 153:976-80.

Halliwell B, Gutteridge JMC. 1989. Free radicals in biology and medicine. New York: Oxford Univ Pr.

Hernandez N, Orozco-Levi M, Belalcazar V, et al. 2003. Dual morphometrical changes of the deltoid muscle in patients with COPD. Respir Physiol Neurobiol, 134:219-29.

Heunks LM, Vina J, van Herwaarden CL, et al. 1999. Xanthine oxidase is involved in exercise-induced oxidative stress in chronic obstructive pulmonary disease. Am J Physiol, 277:R1697-R1704.

Hidalgo C, Sanchez G, Barrientos G, et al. 2006. A transverse tubule NADPH oxidase activity stimulates calcium release from isolated triads via ryanodine receptor type $1 \mathrm{~S}$-glutathionylation. $J$ Biol Chem, 281:26473-82.

Hopkinson NS, Man WD, Dayer MJ, et al. 2004. Acute effect of oral steroids on muscle function in chronic obstructive pulmonary disease. Eur Respir J, 24:137-42.

Hopkinson NS, Tennant RC, Dayer MJ, et al. 2007. A prospective study of decline in fat free mass and skeletal muscle strength in chronic obstructive pulmonary disease. Respir Res, 8:25-32.

Hoppeler H, Kleinert E, Schlegel C, et al. 1990. Morphological adaptations of human skeletal muscle to chronic hypoxia. Int J Sports Med, 11(Suppl 1):S3-S9.

Houmard JA, Weidner ML, Gavigan KE, et al. 1998. Fiber type and citrate synthase activity in the human gastrocnemius and vastus lateralis with aging. J Appl Physiol, 85:1337-41.

Huey KA, Roy RR, Zhong H, et al. 2008. Time-dependent changes in caspase-3 activity and heat shock protein 25 after spinal cord transection in adult rats. Exp Physiol, 93:415-25.

Hussain SN, Matar G, Barreiro E, et al. 2006. Modifications of proteins by 4-hydroxy-2-nonenal in the ventilatory muscles of rats. Am J Physiol Lung Cell Mol Physiol, 290:L996-1003. 
Hussain SNA, Stewart DJ, Ludemann JP, et al. 1992. The role of endothelium-derived relaxing factors (EDRF) in active hyperaemia of the canine diaphragm. J Appl Physiol, 72:2393-401.

Jakobsson P, Jorfeldt L, Brundin A. 1990. Skeletal muscle metabolites and fibre types in patients with advanced chronic obstructive pulmonary disease (COPD), with and without chronic respiratory failure. Eur Respir J, 3:192-6.

Javeshghani D, Magder S, Barreiro E, et al. 2002. Molecular characterization of a superoxide-generating $\mathrm{NAD}(\mathrm{P}) \mathrm{H}$ oxidase in the ventilatory muscles. Am J Resp Crit Care Med, 165:412-8.

Jeffery MM, Kufel TJ, Pineda L. 2000. Quadriceps fatigue after cycle exercise in patients with chronic obstructive pulmonary disease. Am J Respir Crit Care Med, 161:447-53.

Jobin J, Maltais F, Doyon JF, et al. 1998. Chronic obstructive pulmonary disease: capillarity and fiber-type characteristics of skeletal muscle. J Cardiopulm Rehabil, 18:432-7.

Johannessen M, Moller S, Hansen T, et al. 2006. The multifunctional roles of the four-and-a-half-LIM only protein FHL2. Cell Mol Life Sci, 63:268-84.

Kanski J, Hong SJ, Schoneich C. 2005. Proteomic analysis of protein nitration in aging skeletal muscle and identification of nitrotyrosinecontaining sequences in vivo by nanoelectrospray ionization tandem mass spectrometry. $J$ Biol Chem, 280:24261-6.

Kapur S, Bedard S, Marcotte B, et al. 1998. Expression of nitric oxide synthase in skeletal muscle: A novel role for nitric oxide as a modulator of insulin action. Diabetes, 46:1691-700.

Killian KJ, LeBlanc P, Martin DH, et al. 1992. Exercise capacity and ventilatory, circulatory, and symptom limitation in patients with chronic airflow limitation. Am Rev Respir Dis, 146:935-40.

Kim E, Bobkova E, Hegyi G, et al. 2002. Actin cross-linking and inhibition of the actomyosin motor. Biochemistry, 41:86-93.

Klebl BM, Ayoub AT, Pette D. 1999. Protein oxidation, tyrosine nitration, and inactivation of sarcoplasmic reticulum $\mathrm{Ca}^{2+}$-ATPase in low-frequency stimulatd rabbit muscle. FEBS Lett, 422:381-4.

Kobzik L, Reid MB, Bredt DS, et al. 1994. Nitric oxide in skeletal muscle. Nature, 372:546-8.

Kobzik L, Stringer B, Balligand JL, et al. 1995. Endothelial type nitric oxide synthase in skeletal muscle fibers:mitochondrial relationship. Biochm Biophys Res Commun, 211:375-81.

Kocturk S, Kayatekin BM, Resmi H, et al. 2008. The apoptotic response to strenuous exercise of the gastrocnemius and solues muscle fibers in rats. Eur J Appl Physiol, 102:515-24.

Koechlin C, Maltais F, Saey D, et al. 2005. Hypoxaemia enhances peripheral muscle oxidative stress in chronic obstructive pulmonary disease. Thorax, 60:834-41.

Kurella EG, Osipov AN, Goldman R, et al. 1995. Inhibition of Na+/K(+)ATPase by phenoxyl radicals of etoposide (VP-16): role of sulfhydryls oxidation. Biochim Biophys Acta, 1232:52-8.

Landbo C, Prescott E, Lange P, et al. 1999. Prognostic value of nutritional status in chronic obstructive pulmonary disease. Am J Respir Crit Care Med, 160:1856-61.

Lando Y, Boiselle PM, Shade D, et al. 1999. Effect of lung volume reduction surgery on diaphragm length in severe chronic obstructive pulmonary disease. Am J Respir Crit Care Med, 159:796-805.

Lands LC, Smountas AA, Mesiano G, et al. 1999. Maximal exercise capacity and peripheral skeletal muscle function following lung transplantation. $J$ Heart Lung Transplant, 18:113-20.

Lange S, Auerbach D, McLoughlin P, et al. 2002. Subcellular targeting of metabolic enzymes to titin in heart muscle may be mediated by DRAL/FHL-2. J Cell Sci, 115:4925-36.

Langen RC, Schols AM, Kelders MC, et al. 2006. Muscle wasting and impaired muscle regeneration in a murine model of chronic pulmonary inflammation. Am J Respir Cell Mol Biol, 35:689-96.

Lawler JM, Song W, Demaree SR. 2003. Hindlimb unloading increases oxidative stress and disrupts antioxidant capacity in skeletal muscle. Free Radic Biol Med, 35:9-16.
Levine S, Gregory C, Nguyen T, et al. 2002. Bioenergetic adaptation of individual human diaphragmatic myofibers to severe COPD. $J$ Appl Physiol, 92:1205-13.

Levine S, Kaiser L, Leferovich J, et al. 1997. Cellular adaptations in the diaphragm in chronic obstructive pulmonary disease. $N$ Engl J Med, 337:1799-806.

Levine S, Nguyen T, Friscia M, et al. 2006. Parasternal intercostal muscle remodeling in severe chronic obstructive pulmonary disease. $J$ Appl Physiol, 101:1297-302.

Levine S, Nguyen T, Kaiser LR, et al. 2003. Human diaphragm remodeling associated with chronic obstructive pulmonary disease: clinical implications. Am J Respir Crit Care Med, 168:706-13.

Lexell J. 1995. Human aging, muscle mass, and fiber type composition. J Gerontol A Biol Sci Med Sci, 50(Spec No):11-6.

Mador MJ, Bozkanat E, Kufel TJ. 2003a. Quadriceps fatigue after cycle exercise in patients with COPD compared with healthy control subjects. Chest, 123:1104-11.

Mador MJ, Deniz O, Aggarwal A, et al. 2003b. Quadriceps fatigability after single muscle exercise in patients with chronic obstructive pulmonary disease. Am J Respir Crit Care Med, 168:102-8.

Mador MJ, Kufel TJ, Pineda LA, et al. 2000. Diaphragmatic fatigue and high-intensity exercise in patients with chronic obstructive pulmonary disease. Am J Respir Crit Care Med, 161:118-23.

Mador MJ, Kufel TJ, Pineda LA, et al. 2001. Effect of pulmonary rehabilitation on quadriceps fatiguability during exercise. Am J Respir Crit Care Med, 163: 930-5.

Malaguti C, Nery LE, Dal CS, et al. 2006. Scaling skeletal muscle function to mass in patients with moderate-to-severe COPD. Eur J Appl Physiol, 98:482-8.

Maltais F, LeBlanc P, Whittom F, et al. 2000. Oxidative enzyme activities of the vastus lateralis muscle and the functional status in patients with COPD. Thorax, 55:848-53.

Maltais F, Simard AA, Simard C, et al. 1996. Oxidative capacity of the skeletal muscle and lactic acid kinetics during exercise in normal subjects and in patients with COPD. Am J Respir Crit Care Med, 153:288-93

Maltais F, Sullivan MJ, LeBlanc P, et al. 1999. Altered expression of myosin heavy chain in the vastus lateralis muscle in patients with COPD. Eur Respir J, 13:850-4.

Marquis K, Debigare R, Lacasse Y, et al. 2002. Midthigh muscle crosssectional area is a better predictor of mortality than body mass index in patients with chronic obstructive pulmonary disease. Am J Respir Crit Care Med, 166:809-13.

Martin B, Schneider R, Janetzky S, et al. 2002. The LIM-only protein FHL2 interacts with beta-catenin and promotes differentiation of mouse myoblasts. J Cell Biol, 159:113-22.

McLoughlin DM, Spargo E, Wassif WS, et al. 1998. Structural and functional changes in skeletal muscle in anorexia nervosa. Acta Neuropathol, 95:632-40.

Mercken EM, Hageman GJ, Schols AM, et al. 2005. Rehabilitation decreases exercise-induced oxidative stress in chronic obstructive pulmonary disease. Am J Respir Crit Care Med, 172:994-1001.

Milzani A, Rossi R, Di Simplicio P, et al. 2000. The oxidation produced by hydrogen peroxide on Ca-ATP-G-actin. Protein Sci, 9:1774-82.

Montes de Oca M, Loeb E, Torres SH, et al. 2008. Peripheral muscle alterations in non-COPD smokers. Chest, 133:13-8.

Montes de Oca M, Torres SH, De SJ, et al. 2005. Skeletal muscle inflammation and nitric oxide in patients with COPD. Eur Respir J, 26:390-7.

Montes de Oca M, Torres SH, Gonzalez Y, et al. 2006. Peripheral muscle composition and health status in patients with COPD. Respir Med, 100:1800-6

Mostert R, Goris A, Weling-Scheepers C, et al. 2000. Tissue depletion and health related quality of life in patients with chronic obstructive pulmonary disease. Respir Med, 94:859-67.

Murray J, Taylor SW, Zhang B, et al. 2003. Oxidative damage to mitochondrial complex I due to peroxynitrite: identification of reactive tyrosines by mass spectrometry. J Biol Chem, 278:37223-30. 
Nishimura Y, Tsutsumi M, Nakata H, et al. 1995. Relationship between respiratory muscle strength and lean body mass in men with COPD. Chest, 107:1232-6.

Orozco-Levi M. 2003. Structure and function of the respiratory muscles in patients with COPD: impairment or adaptation? Eur Respir J Suppl, 46:41s-51s.

Orozco-Levi M, Gea J, Lloreta JL, et al. 1999. Subcellular adaptation of the human diaphragm in chronic obstructive pulmonary disease. Eur Respir J, 13:371-8.

Orozco-Levi M, Lloreta J, Minguella J, et al. 2001. Injury of the human diaphragm associated with exertion and chronic obstructive pulmonary disease. Am J Respir Crit Care Med, 164:1734-9.

Ostrowski K, Rohde T, Zacho M, et al. 1998. Evidence that interleukin-6 is produced in human skeletal muscle during prolonged running. J Physiol, 508(Pt 3):949-53.

Ottenheijm CA, Heunks LM, Hafmans T, et al. 2006a. Titin and diaphragm dysfunction in chronic obstructive pulmonary disease. Am J Respir Crit Care Med, 173:527-34.

Ottenheijm CA, Heunks LM, Li YP, et al. 2006b. Activation of the ubiquitinproteasome pathway in the diaphragm in chronic obstructive pulmonary disease. Am J Respir Crit Care Med, 174:997-1002.

Ottenheijm CA, Heunks LM, Sieck GC, et al. 2005. Diaphragm dysfunction in chronic obstructive pulmonary disease. Am J Respir Crit Care Med, 172:200-5.

Petersen AM, Magkos F, Atherton P, et al. 2007a. Smoking impairs muscle protein synthesis and increases the expression of myostatin and MAFbx in muscle. Am J Physiol Endocrinol Metab, 293:E843-E848.

Petersen AM, Penkowa M, Iversen M, et al. 2007b. Elevated levels of IL-18 in plasma and skeletal muscle in chronic obstructive pulmonary disease. Lung, 185:161-171.

Pierce AP, de Waal E, McManus LM, et al. 2007. Oxidation and structural perturbation of redox-sensitive enzymes in injured skeletal muscle. Free Radic Biol Med, 43:1584-93.

Pinto-Plata VM, Mullerova H, Toso JF, et al. 2006. C-reactive protein in patients with COPD, control smokers and non-smokers. Thorax, 61:23-28.

Polkey MI, Harris ML, Hughes PD, et al. 1997. The contractile properties of the elderly human diaphragm. Am J Respir Crit Care Med, 155:1560-4.

Polkey MI, Kyroussis D, Hamnegard CH, et al. 1996. Diaphragm strength in chronic obstructive pulmonary disease. Am J Respir Crit Care Med, 154:1310-17.

Proctor DN, Sinning WE, Walro JM, et al. 1995. Oxidative capacity of human muscle fiber types: effects of age and training status. $J$ Appl Physiol, 78:2033-8.

Rahman I, Morrison D, Donaldson K, et al. 1996. Systemic oxidative stress in asthma, COPD, and smokers. Am J Respir Crit Care Med, 154:1055-60.

Reid MB. 1996. Reactive oxygen and nitric oxide in skeletal muscle. News Physiol Sci, 11:114-9.

Reid MB, Lannergren J, Westerblad H. 2002. Respiratory and limb muscle weakness induced by tumor necrosis factor-alpha: involvement of muscle myofilaments. Am J Respir Crit Care Med, 166:479-84.

Remels AH, Schrauwen P, Broekhuizen R, et al. 2007. Peroxisome proliferator-activated receptor expression is reduced in skeletal muscle in COPD. Eur Respir J, 30:245-52.

Richardson RS, Leek BT, Gavin TP, et al. 2004. Reduced mechanical efficiency in chronic obstructive pulmonary disease but normal peak VO2 with small muscle mass exercise. Am J Respir Crit Care Med, 169:89-96.

Roberts CK, Barnard RJ, Scheck SH, et al. 1998. Exercise-stimulated glucose transport in skeletal muscle is nitric oxide dependent. Am J Physiol, 273:E220-E225.

Russell AP, Somm E, Debigare R, et al. 2004. COPD results in a reduction in UCP3 long mRNA and UCP3 protein content in types I and IIa skeletal muscle fibers. J Cardiopulm Rehabil, 24:332-9.

Saey D, Cote CH, Mador MJ, et al. 2006. Assessment of muscle fatigue during exercise in chronic obstructive pulmonary disease. Muscle Nerve, 34:62-71.
Saey D, Debigare R, LeBlanc P, et al. 2003. Contractile leg fatigue after cycle exercise: a factor limiting exercise in patients with chronic obstructive pulmonary disease. Am J Respir Crit Care Med, 168:425-30.

Saey D, Michaud A, Couillard A, et al. 2005. Contractile fatigue, muscle morphometry, and blood lactate in chronic obstructive pulmonary disease. Am J Respir Crit Care Med, 171:1109-15.

Sandri M, Sandri C, Gilbert A, et al. 2004. Foxo transcription factors induce the atrophy-related ubiquitin ligase atrogin-1 and cause skeletal muscle atrophy. Cell, 117:399-412.

Sauleda J, Garcia-Palmer F, Wiesner RJ, et al. 1998. Cytochrome oxidase activity and mitochondrial gene expression in skeletal muscle of patients with chronic obstructive pulmonary disease. Am J Respir Crit Care Med, 157:1413-7.

Schols AM, Buurman WA, Staal van den Brekel AJ, et al. 1996. Evidence for a relation between metabolic derangements and increased levels of inflammatory mediators in a subgroup of patients with chronic obstructive pulmonary disease. Thorax, 51:819-24.

Schols AM, Soeters PB, Dingemans AM, et al. 1993. Prevalence and characteristics of nutritional depletion in patients with stable COPD eligible for pulmonary rehabilitation. Am Rev Respir Dis, 147:1151-6.

Scott SV, Klionsky DJ. 1998. Delivery of proteins and organelles to the vacuole from the cytoplasm. Curr Opin Cell Biol, 10:523-9.

Serres I, Gautier V, Varray A, et al. 1998. Impaired skeletal muscle endurance related to physical inactivity and altered lung function in COPD patients. Chest, 113:900-5.

Shee CD, Cameron IR. 1990. The effect of $\mathrm{pH}$ and hypoxia on function and intracellular $\mathrm{pH}$ of the rat diaphragm. Respir Physiol, 79:57-68.

Souza JM, Radi R. 1998. Glyceraldehyde-3-phosphate dehydrogenase inactivation by peroxynitrite. Arch Biochem Biophys, 360:187-94.

Spruit MA, Gosselink R, Troosters T, et al. 2003. Muscle force during an acute exacerbation in hospitalised patients with COPD and its relationship with CXCL8 and IGF-I. Thorax, 58:752-6.

Stamler JS, Meissner G. 2001. Physiology of nitric oxide in skeletal muscle. Physiol Rev, 81:209-37.

Steinberg HO, Brechtel G, Johnson A, et al. 1994. Insulin-mediated skeletal muscle vasodilation is nitric oxide dependent. A novel action of insulin to increase nitric oxide release. J Clin Invest, 94:1172-9.

Stitt TN, Drujan D, Clarke BA, et al. 2004. The IGF-1/PI3K/Akt pathway prevents expression of muscle atrophy-induced ubiquitin ligases by inhibiting FOXO transcription factors. Mol Cell, 14:395-403.

Stubbings AK, Moore AJ, Dusmet M, et al. 2008. Physiological properties of human diaphragm muscle fibres and the effect of chronic obstructive pulmonary disease. $J$ Physiol, 586:2637-50.

Sun J, Xin C, Eu JP, et al. 2001. Cysteine-3635 is responsible for skeletal muscle ryanodine receptor modulation by NO. Proc Natl Acad Sci US A, 98:11158-62.

Supinski GS, Callahan LA. 2006. Caspase activation contributes to endotoxin-induced diaphragm weakness. J Appl Physiol, 100:1770-7.

Swallow EB, Gosker HR, Ward KA, et al. 2007a. A novel technique for nonvolitional assessment of quadriceps muscle endurance in humans. J Appl Physiol, 103:739-46.

Swallow EB, Reyes D, Hopkinson NS, et al. 2007b. Quadriceps strength predicts mortality in patients with moderate to severe chronic obstructive pulmonary disease. Thorax, 62:115-20.

Takabatake N, Nakamura H, Abe S, et al. 2000. The relationship between chronic hypoxemia and activation of the tumor necrosis factor-alpha system in patients with chronic obstructive pulmonary disease. Am J Respir Crit Care Med, 161:1179-84.

Thomas GD, Sander M, Lau KS, et al. 1998. Impaired metabolic modulation of alpha-adrenergic vasoconstriction in dystrophin-deficient skeletal muscle. Proc Natl Acad Sci U S A, 95:15090-5.

Thomas GD, Victor RG. 1998. Nitric oxide mediates contraction-induced attenuation of sympathetic vasoconstriction in rat skeletal muscle. J Physiol, 506(Pt 3):817-26.

Tolep K, Higgins N, Muza S, et al. 1995. Comparison of diaphragm strength between healthy adult elderly and young men. Am J Respir Crit Care Med, 152:677-82. 
Valerio A, Cardile A, Cozzi V, et al. 2006. TNF-alpha downregulates eNOS expression and mitochondrial biogenesis in fat and muscle of obese rodents. J Clin Invest, 116:2791-8.

Van't HA, Harlaar J, Gosselink R, et al. 2004. Quadriceps muscle endurance in patients with chronic obstructive pulmonary disease. Muscle Nerve, 29:267-74.

Vassilakopoulos T, Divangahi M, Rallis G, et al. 2004. Differential cytokine gene expression in the diaphragm in response to strenuous resistive breathing. Am J Respir Crit Care Med, 170:154-61.

Vassilakopoulos T, Govindaraju K, Parthenis D, et al. 2007. Nitric oxide production in the ventilatory muscles in response to acute resistive loading. Am J Physiol Lung Cell Mol Physiol, 292:L1013-22.

Vassilakopoulos T, Katsaounou P, Karatza MH, et al. 2002. Strenuous resistive breathing induces plasma cytokines: role of antioxidants and monocytes. Am J Respir Crit Care Med, 166:1572-8.

Vassilakopoulos T, Zakynthinos S, Roussos C. 1999. Strenuous resistive breathing induces proinflammatory cytokines and stimulates the HPA axis in humans. Am J Physiol, 277:R1013-9.

Vermeeren MA, Schols AM, Wouters EF. 1997. Effects of an acute exacerbation on nutritional and metabolic profile of patients with COPD. Eur Respir J, 10:2264-9.

Vernooy JH, Kucukaycan M, Jacobs JA, et al. 2002. Local and systemic inflammation in patients with chronic obstructive pulmonary disease: soluble tumor necrosis factor receptors are increased in sputum. $\mathrm{Am} \mathrm{J}$ Respir Crit Care Med, 166:1218-24.

Vina J, Servera E, Asensi M, et al. 1996. Exercise causes blood glutathione oxidation in chronic obstructive pulmonary disease: Prevention by O-2 therapy. J Appl Physiol, 81:2199-202.
Viner RI, Ferrington DA, Aced GI, et al. 1997. In vivo aging of rat skeletal muscle sarcoplasmic reticulum $\mathrm{Ca}-\mathrm{ATPase}$. Chemical analysis and quantitative simulation by exposure to low levels of peroxyl radicals. Biochim Biophys Acta, 1329:321-35.

Wei Y, Sowers JR, Nistala R, et al. 2006. Angiotensin II-induced NADPH oxidase activation impairs insulin signaling in skeletal muscle cells. J Biol Chem, 281:35137-46.

Whittom F, Jobin J, Simard PM, et al. 1998. Histochemical and morphological characteristics of the vastus lateralis muscle in patients with chronic obstructive pulmonary disease. Med Sci Sports Exerc, 30:1467-74.

Wijnhoven HJ, Heunks LM, Geraedts MC, et al. 2006. Oxidative and nitrosative stress in the diaphragm of patients with COPD. Int J Chron Obstruct Pulmon Dis, 1:173-9.

Wilcox P, Milliken C, Bressler B. 1996. High-dose tumor necrosis factor alpha produces an impairment of hamster diaphragm contractility. Attenuation with a prostaglandin inhibitor. Am J Respir Crit Care Med, 153:1611-5.

Yang Y, Hou H, Haller EM, et al. 2005. Suppression of FOXO1 activity by FHL2 through SIRT1-mediated deacetylation. EMBO J, 24:1021-32.

Yende S, Waterer GW, Tolley EA, et al. 2006. Inflammatory markers are associated with ventilatory limitation and muscle dysfunction in obstructive lung disease in well functioning elderly subjects. Thorax, 61:10-6.

Young A, Stokes M, Crowe M. 1985. The size and strength of the quadriceps muscles of old and young men. Clin Physiol, 5:145-54.

Zattara-Hartmann MC, Badier M, Guillot C, et al. 1995. Maximal force and endurance to fatigue of respiratory and skeletal muscles in chronic hypoxemic patients: the effects of oxygen breathing. Muscle Nerve, 18:495-502. 